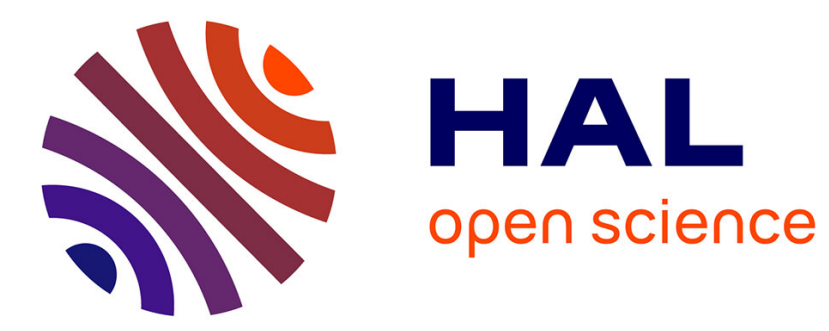

\title{
Design of Semicrystalline Elastomeric Glassy Triblock Copolymers from Oligoamide-Based RAFT Agents
}

Senbin Chen, Pierre Alcouffe, Alain Rousseau, Jean-François Gérard, Frédéric Lortie, Jintao Zhu, Julien Bernard

\section{- To cite this version:}

Senbin Chen, Pierre Alcouffe, Alain Rousseau, Jean-François Gérard, Frédéric Lortie, et al.. Design of Semicrystalline Elastomeric Glassy Triblock Copolymers from Oligoamide-Based RAFT Agents. Macromolecules, 2021, 54 (1), pp.94-104. 10.1021/acs.macromol.0c02252 . hal-03357257

\section{HAL Id: hal-03357257 https://hal.science/hal-03357257}

Submitted on 2 Nov 2021

HAL is a multi-disciplinary open access archive for the deposit and dissemination of scientific research documents, whether they are published or not. The documents may come from teaching and research institutions in France or abroad, or from public or private research centers.
L'archive ouverte pluridisciplinaire HAL, est destinée au dépôt et à la diffusion de documents scientifiques de niveau recherche, publiés ou non, émanant des établissements d'enseignement et de recherche français ou étrangers, des laboratoires publics ou privés. 


\title{
Design of Semi-Crystalline Elastomeric Glassy Triblock Copolymers from Oligoamide-based RAFT Agents
}

\author{
Senbin Chen, ${ }^{* 1,2}$ Pierre Alcouffe, ${ }^{2}$ Alain Rousseau, ${ }^{2}$ Jean-François Gérard, ${ }^{2}$ Frédéric Lortie, ${ }^{2}$ Jintao \\ Zhu, ${ }^{* 1}$ and Julien Bernard ${ }^{* 2}$
}

${ }^{1}$ Key Laboratory of Materials Chemistry for Energy Conversion and Storage of Ministry of Education (HUST), School of Chemistry and Chemical Engineering, Huazhong University of Science and Technology (HUST), Wuhan 430074, China

${ }^{2}$ Univ Lyon, INSA Lyon, CNRS, IMP UMR 5223, F-69621, Villeurbanne, France

Correspondence to: J. Bernard (julien.bernard@insa-lyon.fr)

J. Zhu (jtzhu@hust.edu.cn)

S. Chen (senbin@hust.edu.cn)

This paper is dedicated to the memory of our dear colleague and friend, Prof. Jean-Pierre Pascault, who recently passed away. 


\section{ABSTRACT:}

Semi-crystalline-elastomeric-glassy ABC triblock copolymers, consisting of precisely-defined blocks based on oligoamide 11 (OPA11), poly(lauryl methacrylate) (PLMA), and poly(methyl methacrylate) (PMMA) have been designed via the combination of melt polycondensation and reversible-addition fragmentation-transfer (RAFT) polymerization techniques. Semi-crystalline OPA11 prepared via melt polycondensation was equipped with a RAFT agent at the $\omega$-position. The resulting functionalized oligomers were further used to mediate the radical polymerization of methacrylate monomers (LMA and MMA) and generate well-defined OPA11- $b$-PLMA- $b$-PMMA triblock copolymers. AFM observations of the triblock copolymer in bulk revealed a microphase separation consisting in the formation of PMMA domains surrounded by the PLMA matrix, and the presence of additional spherical nanodomains embedded into the PLMA matrix possibly corresponding to OPA11 semi-crystalline regions. The triblocks were finally dissolved into a reactive epoxy-based mixture which was subsequently cured to generate a well-defined nanostructured epoxy-amine network by freezing the ABC triblock reactioninduced phase separation. Thus, the morphology appears as a homogeneous dispersion of nanometric spherical micelles $(\approx 20 \mathrm{~nm}$ diameter) constituted of an elastomeric core of PLMA, an outer shell of PMMA and OPA11 in between. The described synthetic strategy and the proposed block copolymer structures may contribute to future efforts aiming at developing new hierarchically organized polymeric materials, which can be implemented in polymer physics and material science.

KEYWORDS: Thermoplastic elastomers, Crystalline-elastomeric-glassy triblock copolymers, RAFT polymerization, Nanostructured epoxy networks 


\section{INTRODUCTION}

Thermoplastic elastomers (TPE) $)^{1,2}$ are multifunctional polymer materials that possess both the meltprocessability of the thermoplastics and elastic properties of rubber. Typically, TPEs are linear, ${ }^{3-5} \operatorname{star}^{6}$ or brush-shaped ${ }^{7}$ block copolymers (BCPs) that microphase separate into "hard" glassy or/and crystalline domains embedded in a "soft" rubbery matrix. The TPE family includes some examples of linear $\mathrm{ABC}$ triblock copolymers ${ }^{8,9}$ made of crystalline, elastomeric, and glassy blocks prepared by anionic polymerizations, ${ }^{7,10-13}$ ring-opening metathesis polymerization (ROMP), ${ }^{14}$ or by combination of ring-opening polymerization (ROP) with atom transfer radical polymerization (ATRP). ${ }^{15}$ Because crystalline-rubbery-glassy $\mathrm{ABC}$ triblocks combine the specific attributes of each phase, ${ }^{16,17}$ they constitute promising macromolecular tools to develop high performance materials. ${ }^{5,16,18-20}$

Advances in synthetic polymer chemistry during the past two decades, especially reversibledeactivation radical polymerization techniques (RDRP such as ATRP and RAFT) techniques, have significantly broaden the range of monomer structures that can be incorporated into BCPs. Merging step growth processes and RDRP techniques ${ }^{21-23}$ is particularly appealing to develop advanced polymer materials as it affords the production of a number of interesting BCPs with vinylic and polycondensate segments (polystyrenes, polyacrylates, polymethacrylates vs. polyesters, polysulfones, polyurethane, polyethers...) for diverse purposes, i.e., surface patterning or toughening brittle highly crosslinked polymers as pioneered by Bates in the late 90 's. ${ }^{3}$ This last topic has been the subject of much research, ${ }^{16,17,24-28}$ due to the variety of nanostructures that can be built and of mechanical behaviors that can be encountered. Different macromolecular architectures have been used as additives for epoxy resins in order to form nanoscale dispersed structures, such as spherical micelles, worm-like micelles, vesicles or octopus-like nanostructures in epoxy matrix..$^{29,30}$ The nanostructural heterogeneities were considered to determine the physical properties of epoxy thermosets, which were continually used in a variety of 
applications such as coatings, adhesives, and structural composites. ${ }^{31}$ However, to the best of our knowledge, incorporating crystalline-rubbery-glassy triblock copolymers that consist of "epoxy-philic" and "epoxy-phobic" blocks into an epoxy matrix has remained unexplored so far.

In this work, we explore a straightforward strategy to design well-defined crystalline-rubberyglassy $\mathrm{ABC}$ triblock copolymers and investigate their self-assembly in bulk and in reactive epoxy systems. The approach developed herein relies on the facile one-step synthesis of oligomeric of polyamide 11 (OPA11) via melt polycondensation and the consecutive ligation of a relevant dithiobenzoate group on the oligoamide chain ends to generate the oligomeric RAFT agents (Figure 1). The propensity of the resulting oligoRAFT agents to efficiently mediate the radical polymerization of methacrylates has been subsequently studied in order to grow $\mathrm{ABC}$ triblock copolymers. More precisely, we have designed an $\mathrm{ABC}$ block copolymer where the blocks $\mathrm{A}$ and $\mathrm{B}$, respectively constituted of semicrystalline OPA11 and rubbery PLMA are expected to act in concert to toughen the epoxy materials while the glassy block C (PMMA) is necessary to overcome macrophase separation between the block copolymer and the epoxy-amine system. The capability of obtained OPA11-b-PLMA- $b$-PMMA triblock copolymers to self-organize in bulk has been investigated by atomic force microscope (AFM). Furthermore, the idea beneath this synthesis is to blend and self-organize such triblock polymer on a nanometer scale into epoxy precursors solutions, and to subsequently cure the reactive medium to generate nanostructured epoxy-amine networks by freezing the organization during the formation of the network. Taking advantage of the miscibility of the PMMA block in epoxy-amine systems such as DGEBA/MCDEA before and in the course of the network formation, the ability of semi-crystallinerubbery-glassy $\mathrm{ABC}$ triblock to self-organize at the nanometer scale into an epoxy-amine matrix has been finally explored. 


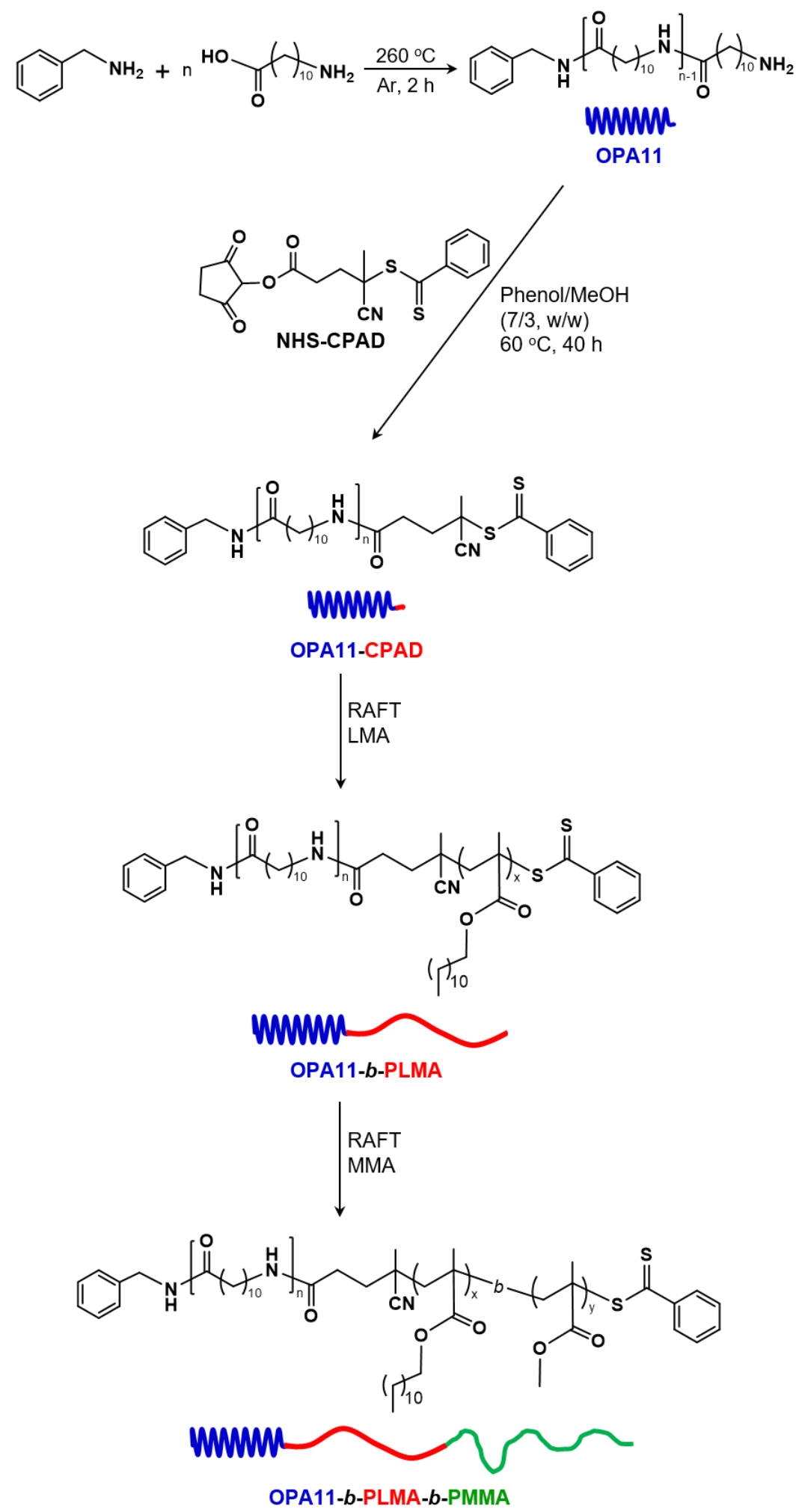

Figure 1. General strategy to prepare semi-crystalline-rubbery-glassy ABC triblock copolymers: OPA11-b-PLMA- $b$-PMMA. 


\section{EXPERIMENTAL SECTION}

Materials. All starting materials, including benzyl amine, 11-aminoundecanoic acid, 4-cyano-4(phenylcarbonothioylthio) pentanoic acid (CPADB), N-hydroxysuccinimide (NHS), dicyclohexylcarbodiimide (DCC), lauryl methylacrylate (LMA), methyl methacrylate (MMA), 2, 2'azobis(isobutyronitrile) (AIBN), diglycidyl ether of bisphenol A (DGEBA, DER332, $\mathrm{M}_{\mathrm{w}}=346 \mathrm{~g}^{\mathrm{m}} \mathrm{mol}^{-1}$ ), 4, 4'-methylene bis-[3-chloro 2, 6-diethylaniline] (MCDEA), were purchased from Aldrich or Fluka. The solvents were ordered from Carlo Erba. LMA was diluted with cyclohexane, then washed with 5\% $\mathrm{NaOH}$ solution $(3 \times 50 \mathrm{~mL})$ and distilled water $(3 \times 50 \mathrm{~mL})$. The organic phase was filtered prior to passing through a column of basic aluminium oxide to remove the inhibitor. At last the cyclohexane was removed in a rotavapor under reduced pressure and at low temperature $\left(\leq 30{ }^{\circ} \mathrm{C}\right)$. MMA was filtered prior to passing through a column of basic aluminium oxide to remove inhibitors. AIBN was recrystallized twice from ethanol. Unless otherwise indicated the other chemicals were used without further purification.

Characterization Methods. ${ }^{1} \mathrm{H}$ and ${ }^{13} \mathrm{C}$ NMR spectra were recorded on a Bruker AVANCE250 (250 $\mathrm{MHz}$ ) or AVANCE400 (400 MHz) spectrometer using $\mathrm{CDCl}_{3}$, mixture of $\mathrm{CDCl}_{3}$ with trifluoroacetic anhydride (TFAA) or 1, 1, 1, 3, 3, 3-hexafluoro-2-propanol (HFIP). All the obtained polymers were analyzed by SEC with an apparatus running in THF at $25{ }^{\circ} \mathrm{C}$ (flow rate: $1 \mathrm{~mL}^{\circ} \mathrm{min}^{-1}$ ) and equipped with a Viscotek VE 1121 automatic injector, three Waters HR1 (effective molar mass range 100-5000 g/mol, employed for OPA11 analysis) or HR5E (effective molar mass range 2000-4000000 g/mol, employed for OPA11- $b$-PLMA and OPA11- $b$-PLMA- $b$-PMMA analysis) columns and a differential refractive index detector (Viscotek VE3580). The average molar masses of OPA11, OPA11-b-PLMA and OPA11$b$-PLMA- $b$-PMMA were derived from a calibration curve based on PS and PMMA standards, respectively. 
Differential scanning calorimetry (DSC) analyses were carried out on a TA Q20 calorimeter. DSC capsules containing about 5-15 mg of polymers were heated from -100 to $250{ }^{\circ} \mathrm{C}$ at a heating rate of 10 ${ }^{\circ} \mathrm{C} / \mathrm{min}$. The glass transition temperatures $\left(T_{\mathrm{g}}\right)$ were taken as the midpoint of the heat capacity change during the second heating cycle.

To perform atomic force microscopy (AFM) measurements, silicon substrates (approximately $1 \times 1$ $\mathrm{cm}^{2}$ ) were cleaned by ozonolysis treatment. Samples were prepared by spin-coating from dichloromethane (DCM) solution $(2 \mathrm{~g} / \mathrm{L}, 2800 \mathrm{rpm}, 30 \mathrm{~s})$, and then annealed at $180^{\circ} \mathrm{C}$ under vacuum for 3 days. AFM images were acquired in air at room temperature using a Nanoscope IIIa Multimode (Digital Instruments/VEECO, CA). Intermittent contact imaging (i.e., tapping mode) was performed at a scan rate of $1 \mathrm{~Hz}$. Uncoated silicon probes with a resonant frequency between 280 and $405 \mathrm{kHz}$, a spring constant 20 and $80 \mathrm{~N} / \mathrm{m}$, length of 115-135 $\mu \mathrm{m}$, width of 30-40 $\mu \mathrm{m}$, and nominal tip radius of curvature less than $10 \mathrm{~nm}$ were used. Images were displayed and analyzed using the Nanoscope 6.14R1 software.

Transmission electron microscopy (TEM) analysis was performed on Philips CM120 transmission electron microscope with an accelerating voltage of $80 \mathrm{kV}$. Epoxy samples were trimmed using an ultramicrotome and the slices (60-70 nm in thickness) were placed in 300 mesh copper grids for observation. The grids were subsequently exposed to $\mathrm{RuO}_{4}$ vapors (2\% wt of Ruthenium III chloride in 50/50 water/sodium hypochlorite solution) for 25 min to stain.

Synthesis of OPA11. A series of oligoamides 11 (OPA11) $\left(D P_{n}=6,10,15\right)$ were synthesised by a solventless melt polycondensation reaction between benzyl amine and 11-aminoundecanoic acid. Typically, the 11-aminoundecanoic acid $(25.0 \mathrm{~g}, 124.18 \mathrm{mmol})$ was mixed with appropriate quantity of benzyl amine (adjusted to tune the $D P_{n}$ of the oligomers) in a $500 \mathrm{~mL}$ glass flask equipped with a mechanical stirrer, then heated to $260{ }^{\circ} \mathrm{C}$ for $2 \mathrm{~h}$ under argon flow. After cooling down, the obtained OPA11 were conveniently purified by precipitation in methanol to remove residual benzyl amine, 
revealing approximately quantitative yields, subsequently analysed by NMR in the mixture of $\mathrm{CDCl}_{3}$ and TFAA at $25{ }^{\circ} \mathrm{C} .{ }^{1} \mathrm{H}$ NMR $\left(\mathrm{CDCl}_{3} / \mathrm{TFAA}, 3 / 1, \mathrm{v} / \mathrm{v}, \delta, \mathrm{ppm}, \mathrm{n}=\right.$ number of repeating units in OPA11 backbone): 1.22 (br,-CO- $\left.\left(\mathrm{CH}_{2}\right)_{2}-\left(\mathrm{CH}_{2}\right)_{6}-\left(\mathrm{CH}_{2}\right)_{2}-\mathrm{N}\left(\mathrm{COCF}_{3}\right)^{-}, 12 \mathrm{nH}\right), 1.52$ (br,- $\mathrm{CO}-\mathrm{CH}_{2}-\mathrm{CH}_{2}-\left(\mathrm{CH}_{2}\right)_{6^{-}}$ $\left.\mathrm{CH}_{2}-\mathrm{CH}_{2}-\mathrm{N}\left(\mathrm{COCF}_{3}\right)_{-}, 4 \mathrm{nH}\right), 2.70\left(\mathrm{t},-\mathrm{CO}-\mathrm{CH}_{2}-\left(\mathrm{CH}_{2}\right)_{9}-\mathrm{N}\left(\mathrm{COCF}_{3}\right)-,, 2 \mathrm{nH}\right), 3.30$ (q,-CO-( $\left.\mathrm{CH}_{2}\right)_{9}-\mathrm{CH}_{2}-\mathrm{NH}-$ $\left.\mathrm{COCF}_{3}, 2 \mathrm{H}\right), 3.62\left(\mathrm{t},-\mathrm{CO}-\left(\mathrm{CH}_{2}\right)_{9}-\mathrm{CH}_{2}-\mathrm{N}\left(\mathrm{COCF}_{3}\right)-, 2 \mathrm{nH}\right), 4.91\left(\mathrm{~s}, \mathrm{Ph}_{-} \mathrm{CH}_{2}-\mathrm{N}\left(\mathrm{COCF}_{3}\right)-, 2 \mathrm{H}\right), 6.69$ (s, $\left.\mathrm{CO}-\left(\mathrm{CH}_{2}\right)_{10}-\mathrm{NH}-\mathrm{COCF}_{3}, 1 \mathrm{H}\right), 7.08(\mathrm{~d}, 2,6-\mathrm{Ph} H, 2 \mathrm{H}), 7.22(\mathrm{t}, 3,4,5-\mathrm{Ph} H, 3 \mathrm{H}), 11.02\left(\mathrm{~s}, \mathrm{CF}_{3} \mathrm{COOH}, 1 \mathrm{H}\right)$. Synthesis of NHS-CPADB. The activated ester NHS-CPADB was synthesized with slight modifications according to the method developed by Charreyre and others. ${ }^{32}$ 4-Cyano-4-(phenylcarbonothioylthio) pentanoic acid (CPADB) (2g, 7.2mmol), N-hydroxysuccinimide (NHS) $(0.98 \mathrm{~g}, 8.5 \mathrm{mmol}, 1.2 \mathrm{eq})$, and dicyclohexylcarbodiimide (DCC) $(2.22 \mathrm{~g}, 8.5 \mathrm{mmol}, 1.2 \mathrm{eq})$ were mixed together in anhydrous $\mathrm{CHCl}_{3}$ at room temperature and reacted for $12 \mathrm{~h}$. The solvent was then evaporated and ethyl acetate was added to the residue. The obtained suspension was filtered. The filtrate was recovered and the solvent was evaporated resulting in red solid NHS-CPADB, which was dried under vacuum and used for the functionalization of OPA11 without further purification.

Synthesis of OPA11-CPADB. Freshly synthesized OPA11 (100mg) and NHS-CPADB (5 eq) were mixed together in $1 \mathrm{~mL}$ of phenol/methanol $(7 / 3$, wt $\%)$, then stirred at $60{ }^{\circ} \mathrm{C}$ for $40 \mathrm{~h}$. The reaction solution was subsequently precipitated in methanol. The pink precipitate (OPA11-CPADB) was collected and dried under vacuum, then characterized by NMR in a mixture of $\mathrm{CDCl}_{3}$ and TFAA or HFIP at $25{ }^{\circ} \mathrm{C} .{ }^{1} \mathrm{H}$ NMR $\left(\mathrm{CDCl}_{3} / \mathrm{TFAA}, 3 / 1, \mathrm{v} / \mathrm{v}, \delta, \mathrm{ppm}, \mathrm{n}=\right.$ number of repeating units in OPA11 backbone, $\mathrm{m}=$ functionality of OPA11 with CPADB): $1.32\left(\mathrm{br},-\mathrm{CO}-\left(\mathrm{CH}_{2}\right)_{2}-\left(\mathrm{CH}_{2}\right)_{6}-\left(\mathrm{CH}_{2}\right)_{2}-\mathrm{N}\left(\mathrm{COCF}_{3}\right)-\right.$, $12 \mathrm{nH}), 1.64$ (br,- $\left.\mathrm{CO}-\mathrm{CH}_{2}-\mathrm{CH}_{2}-\left(\mathrm{CH}_{2}\right)_{6}-\mathrm{CH}_{2}-\mathrm{CH}_{2}-\mathrm{N}\left(\mathrm{COCF}_{3}\right)-, 4 \mathrm{nH}\right), 1.95$ (s, $\mathrm{CH}_{3}-\mathrm{C}(-\mathrm{CN})(-\mathrm{S}-)-\mathrm{CH}_{2-}$, $3 \mathrm{mH}), 2.70\left(\mathrm{t},-\mathrm{CO}-\mathrm{CH}_{2}-\left(\mathrm{CH}_{2}\right)_{9}-\mathrm{N}\left(\mathrm{COCF}_{3}\right)-\&-\mathrm{C}(=\mathrm{O})-\mathrm{CH}_{2}-\mathrm{CH}_{2}-\mathrm{C}(-\mathrm{CN})\left(-\mathrm{CH}_{3}\right)-\mathrm{S}-,, 2 \mathrm{nH}+4 \mathrm{mH}\right), 3.61(\mathrm{t}$, $\left.-\mathrm{CO}-\left(\mathrm{CH}_{2}\right)_{9}-\mathrm{CH}_{2}-\mathrm{N}\left(\mathrm{COCF}_{3}\right)-2 \mathrm{nH}\right), 4.90\left(\mathrm{~s}, \mathrm{Ph}_{-} \mathrm{CH}_{2}-\mathrm{N}\left(\mathrm{COCF}_{3}\right)-, 2 \mathrm{H}\right), 7.09$ (d, 2,6- $\left.\mathrm{Ph} H-\mathrm{CH}_{2}-, 2 \mathrm{H}\right), 7.21$ 
(t, 3,4,5-PhH-CH $\left.2_{2-}^{-}, 3 \mathrm{H}\right), 7.34$ (t, 3,5-PhH-C(=S)-S-, 2mH), 7.58 (t, 4-PhH-C(=S)-S-, mH), 7.90 (d, 2,6$\mathrm{Ph} H$-C(=S)-S-, 2mH), 10.32 (s, $\left.\mathrm{CF}_{3} \mathrm{COOH}, 1 \mathrm{H}\right) .{ }^{13} \mathrm{C} \mathrm{NMR}\left(\mathrm{CDCl}_{3}+\mathrm{HFIP}, \delta, \mathrm{ppm}\right): 24.82,26.21,26.42$, $26.56,27.07,27.15,27.35,29.36,29.45,32.23,34.13,37.16,40.60,43.57,44.56,118.67,126.25$, $128.08,129.44,134.02,137.24,173.15,177.12,224.02$.

General procedure for solution polymerization of LMA. Solution polymerization of LMA was performed using AIBN as initiator and OPA11-CPADB $\left(D P_{n}=6,10,15\right)$ as chain transfer agent. Typically, the polymerization of LMA $(5.26 \mathrm{~mL}, 18 \mathrm{mmol})$ was carried out using AIBN $(0.36 \mathrm{mg}, 2.2 \times$ $\left.10^{-6} \mathrm{~mol}\right)$, OPA11-CPADB $\left(D P_{n}=6,10,15\right)\left(4.5 \times 10^{-5} \mathrm{~mol}\right)$, hexafluoro-isopropanol (HFIP) $(2.6 \mathrm{~mL})$, toluene $(2.6 \mathrm{~mL})$ and trioxane $\left(243 \mathrm{mg}, 2.7 \times 10^{-3} \mathrm{~mol}\right)$ as an internal reference for the measurement of LMA consumption via ${ }^{1} \mathrm{H}$ NMR. A stock solution was transferred into Schlenk tubes which were thoroughly deoxygenated by five consecutive freeze-pump-thaw runs. The tubes were subsequently placed in an oil bath thermostated at $60{ }^{\circ} \mathrm{C}$. The reaction was stopped by plunging the tubes into liquid nitrogen. The polymer was subsequently precipitated twice into methanol in order to eliminate residual monomer, AIBN and trioxane. Further investigations of the conditions allowing for purifying the OPA11- $b$-PLMA diblock copolymers from traces of unfunctionalized OPA11, and unreacted OPA11CPADB, in this view, HFIP was proven to selectively precipitate the BCP (appears as a pink sticky gel) providing that the molecular weight of the PLMA block is higher than $30000 \mathrm{~g} / \mathrm{mol}$.

The incorporation of the OPA11 sequence was assessed by ${ }^{1} \mathrm{H}$ NMR analysis with the appearance of the characteristic methylene peaks of the benzyl end group at $4.90 \mathrm{ppm}$ and methylene peaks next to NH- and -(=O)- groups at 3.60 and $2.69 \mathrm{ppm}$, respectively. The molar masses of OPA11- $b$-PLMA were finally evaluated by ${ }^{1} \mathrm{H}$ NMR $\left(\mathrm{CDCl}_{3} / \mathrm{TFAA}, 10 / 1\right.$, v/v) from relative integration of the PLMA backbone (-O- $\mathrm{CH}_{2}-\mathrm{C}_{11} \mathrm{H}_{23}, 2 \mathrm{nH}, \delta=3.86 \mathrm{ppm}$, with $\mathrm{n}$ being the degree of polymerization) and of methylene protons of benzyl end group in OPA11 ( $\left.\mathrm{Ph}-\mathrm{CH}_{2^{-}}, 2 \mathrm{H}, \delta=4.90 \mathrm{ppm}\right)$. 
General procedure for solution polymerization of MMA. Solution polymerization of MMA was performed using AIBN as initiator and OPA11-b-PLMA $\left(D P_{n}=15\right)$ as macro-CTA. Typically, the polymerization of MMA $\left(2 \mathrm{~mL}, 1.8 \times 10^{-2} \mathrm{~mol}\right)$ was carried out using AIBN $\left(0.27 \mathrm{mg}, 1.65 \times 10^{-6} \mathrm{~mol}\right)$, OPA11- $b$-PLMA $\left(1.16 \mathrm{~g}, 3.3 \times 10^{-5} \mathrm{~mol}\right), \operatorname{HFIP}(2 \mathrm{~mL})$, toluene $(2 \mathrm{~mL})$ and trioxane $\left(243 \mathrm{mg}, 2.7 \times 10^{-3}\right.$ mol) as an internal reference for the measurement of monomers consumption via ${ }^{1} \mathrm{H}$ NMR. A stock solution was transferred into Schlenk tubes which were thoroughly deoxygenated by five consecutive freeze-pump-thaw runs. The tubes were subsequently placed in an oil bath thermostated at $60{ }^{\circ} \mathrm{C}$. The reaction was stopped by plunging the tubes into liquid nitrogen. The polymer was subsequently precipitated twice into methanol in order to eliminate residual monomer and trioxane. The polymer, slight pink powder, was dried under vacuum and characterized by ${ }^{1} \mathrm{H}$ NMR and SEC. The molar masses of the PMMA block was finally evaluated by ${ }^{1} \mathrm{H}$ NMR ( $\mathrm{CDCl}_{3} / \mathrm{TFAA}, 10 / 1$, v/v) from relative integration of the PLMA backbone (-O-CH $\mathrm{CH}_{2}-\mathrm{C}_{11} \mathrm{H}_{23}, 2 \mathrm{nH}, \delta=3.86 \mathrm{ppm}$, with $\mathrm{n}$ being the degree of polymerization), of methylene protons of benzyl end group in OPA11 $\left(\mathrm{Ph}-\mathrm{CH}_{2^{-}}, 2 \mathrm{H}, \delta=4.90 \mathrm{ppm}\right)$ and of characteristic protons of PMMA $\left(\mathrm{CH}_{3}-\mathrm{O}-, 3 \mathrm{mH}, \delta=3.54 \mathrm{ppm}\right.$, with $\mathrm{m}$ being the degree of polymerization).

Preparation of nanostructured epoxy-amine networks. The networks were prepared as previously described. ${ }^{33-35}$ Blends containing different amounts (5, 10 and 20 parts per hundred epoxy resin-phr) and diglycidyl ether of bisphenol A (DGEBA, DER332, $\mathrm{M}_{\mathrm{w}}=346 \mathrm{gmol}^{-1}$ ) were prepared by mechanical stirring in a glass reactor at $180{ }^{\circ} \mathrm{C}$ for $30 \mathrm{~min}$ leading to a homogeneous premix. The diamine comonomer, 4,4'-methylene bis-[3-chloro 2,6-diethylaniline] (MCDEA, stoichiometric ratio of amine to epoxy functions), was then added over $5 \mathrm{~min}$, the mixture was then casted in $50 \mathrm{~mm} \times 50 \mathrm{~mm} \times 1.5 \mathrm{~mm}$ PTFE mold and polymerized for one day at $80{ }^{\circ} \mathrm{C}$, one day at $135^{\circ} \mathrm{C}$ and post-reacted for one day at 180 ${ }^{\circ} \mathrm{C}$. 


\section{RESULTS AND DISCUSSION}

Design of oligoamide functionalized RAFT agents. The marriage of low-(synthesis)-cost yet robust OPA11 with versatile and tolerant RAFT process facilitates the preparation of BCPs with crystallization abilities. To this end, the original oligoRAFT agents OPA11-CPADB have been designed (Figure 1).

Syntheses of OPA11. In a preliminary step, three OPA11 exhibiting degrees of polymerization ranging from 6 to $15\left(D P_{n}=6,10,15\right)$ were synthesized through the melt polycondensation under argon flow to prevent oxidation reactions occurring at high temperature and to extract the formed water. Aiming at controlling the $D P_{n}$ of the oligoamides and generating oligomers bearing a benzyl group at $\alpha$-position and a reactive amine group at $\omega$-position, the polymerization of 11-aminoundecanoic acid was carried out in the presence of various amounts of benzyl amine as chain stopper, leading to nearly quantitative yields of OPA11.

The resulting oligomers exhibit very poor solubility in common organic solvents with the exception of HFIP and phenol/methanol mixtures (7/3, w/w). The obtained OPA11 were thus conveniently purified by precipitation in methanol to remove residual monomers. Fractions of OPA11 were subsequently reacted with TFAA to allow for ${ }^{1} \mathrm{H}$ NMR and SEC characterizations. The conditions of polymerization and the main characteristics of the generated OPA11 are respectively given in Table 1.

Table 1: Characteristics of the OPA11.

\begin{tabular}{ccccccccc}
\hline $\begin{array}{c}D P_{\mathrm{n}}{ }^{\mathrm{a}} \text { of } \\
\text { OPA11 }\end{array}$ & $n^{\mathrm{b}}$ & $\begin{array}{c}M_{\mathrm{n} \text { th }}{ }^{\mathrm{c}} \\
\mathrm{g} / \mathrm{mol}\end{array}$ & $\begin{array}{c}M_{\mathrm{n} \mathrm{NMR}}{ }^{\mathrm{a}} \\
\mathrm{g} / \mathrm{mol}^{2}\end{array}$ & $\begin{array}{c}M_{\mathrm{n} \text { Titration }}{ }^{\mathrm{d}} \\
\mathrm{g} / \mathrm{mol}\end{array}$ & $\begin{array}{c}M_{\mathrm{n} \text { SEC }}{ }^{\mathrm{e}} \\
\mathrm{g} / \mathrm{mol}\end{array}$ & $\bigoplus^{\mathrm{e}}$ & $\begin{array}{c}T_{\mathrm{m}}{ }^{\mathrm{f}} \\
{ }^{\circ} \mathrm{C}\end{array}$ & $\begin{array}{c}X_{\mathrm{c}}^{\mathrm{f}} \\
\%\end{array}$ \\
\hline 6 & 4 & 1000 & 1300 & 1400 & 900 & 1.68 & 152 & 36 \\
10 & 8 & 1600 & 1700 & 1600 & 1300 & 1.73 & 163 & 34 \\
15 & 13 & 2500 & 2900 & 3000 & 2000 & 2.01 & 171 & 33
\end{tabular}

a: Determined by ${ }^{1} \mathrm{H}$ NMR in $\mathrm{CDCl}_{3}$ at $25{ }^{\circ} \mathrm{C}$, (OPA11 samples were trifluoroacetylated with TFAA prior to perform ${ }^{1} \mathrm{H}$ NMR), from relative integration of the methylene protons of the benzyl end group and OPA11 backbone peaks. ${ }^{\mathrm{b}}: n$ represents the initial ratio between 11 -aminoundecanoic acid and 
benzyl amine. ${ }^{c}$ : calculation of theoretical molar mass assuming that all the 11-aminoundecanoic acid and benzyl amine are consumed. ${ }^{\mathrm{d}}$ : Amino group titration performed by potentiometry in a m-cresol solution using perchloric acid as reagent. ${ }^{\mathrm{e}}$ : OPA11 samples were reacted with TFAA prior to perform SEC in THF (PS calibration). ${ }^{\mathrm{f}}$ : Obtained from DSC analysis $\left(2^{\text {nd }}\right.$ cycle), the crystallinity ratio $\left(\mathrm{X}_{\mathrm{c}}\right)$ of the OPA11 was obtained according to the following definition: $\mathrm{X}_{\mathrm{c}}=\Delta \mathrm{H}_{\mathrm{c}} / \Delta \mathrm{H}_{\mathrm{c} \infty}$, where $\Delta \mathrm{H}_{\mathrm{c}}$ and $\Delta \mathrm{H}_{\mathrm{c} \infty}$ are heats of melting of measured sample and fully crystalline PA11, respectively, $\Delta \mathrm{H}_{\mathrm{c} \infty}=206 \mathrm{~J}^{-1} \mathrm{for} 100 \%$ crystalline PA11. ${ }^{36}$

As illustrated by Table 1, incorporating benzyl amine within 11-aminoundecanoic acid constitutes a simple and efficient way of controlling the overall degree of polymerization of the oligoamides

(Figure 2A).
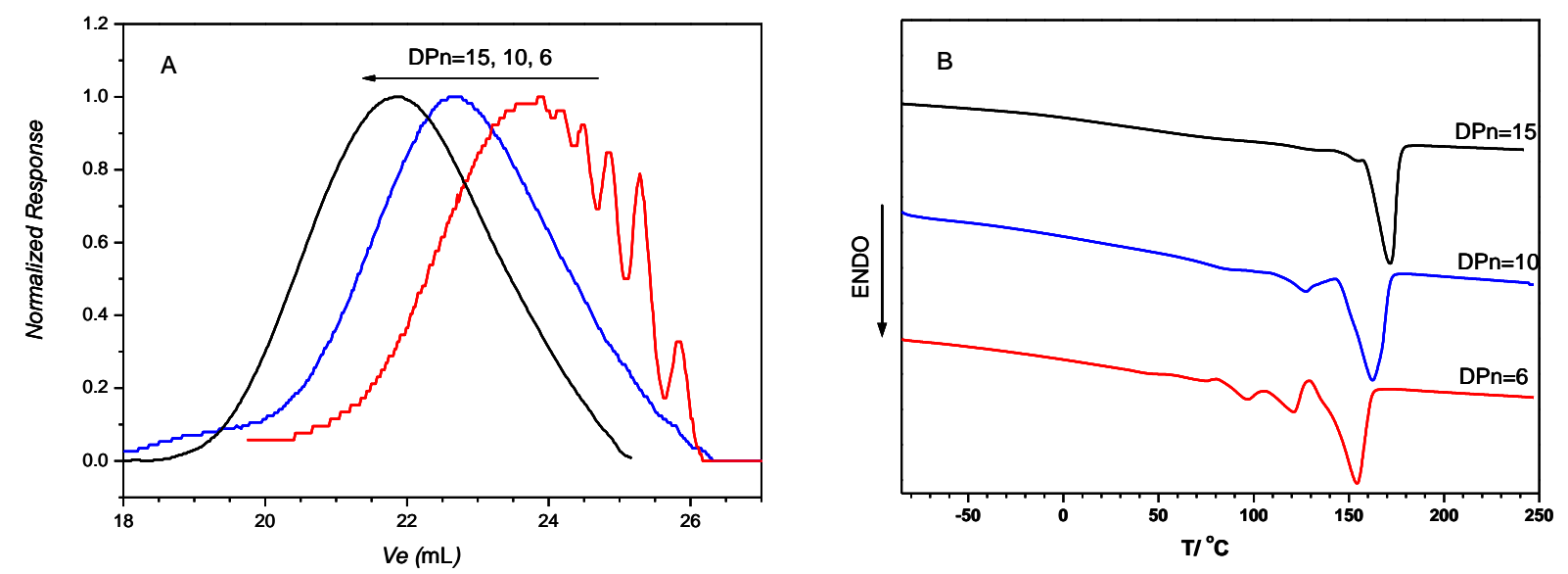

Figure 2: (A) Normalized SEC traces of TFAA-modified OPA11 (THF as eluent). (B) DSC curve of the neat OPA11s $\left(2^{\text {nd }}\right.$ cycle $)$.

The thermal properties of the oligomers were subsequently investigated by DSC (Figure 2B). As expected, all the samples exhibit a crystalline character. Tuning the degree of polymerization of the OPA11 has a significant impact on the properties of the resulting materials. As seen in Figure $2 \mathrm{~B}$, the shortest OPA11s $\left(D P_{\mathrm{n}}=6\right.$ and 10) display a complex thermal behavior with several successive endothermic peaks (including a major peak at respectively 152 and $163{ }^{\circ} \mathrm{C}$ ) possibly corresponding to the melting of crystalline phases of different nature or to consecutive crystallization/melting processes. ${ }^{37}$ In contrast, the longest oligomer (15 repeating units) exhibits a more classical behavior with one melting 
temperature $\left(T_{m}=171{ }^{\circ} \mathrm{C}\right.$ for $\left.D P_{\mathrm{n}}=15\right)$. No matter the considered OPA11, crystallinity ratio around $30 \%$ is measured. It is also worth mentioning that the glass transition temperatures of synthesized OPA11s (expected to be below $50{ }^{\circ} \mathrm{C}$ ) could not be detected on DSC traces.

Synthesis of oligoamide functionalized RAFT agents (oligoRAFT). The presence of an amine group in $\omega$-position of OPA11 was further exploited to generate original oligoRAFT agents with OPA11 being part of the " $\mathrm{R}$ " leaving/initiating group. Relying on a procedure reported by Charreyre and others, ${ }^{32}$ the ligation on the OPA11s of a dithiobenzoate mediating agent capable to polymerize methacrylates was achieved through amidation reaction involving CTAs bearing an (succinimidyl) activated ester group (Figure 1).

After purification by precipitation in methanol, the oligoamide functionalized RAFT agents were analyzed by ${ }^{1} \mathrm{H}$ NMR in $\mathrm{CDCl}_{3}$ after reaction with TFAA (Figure 3B), and ${ }^{13} \mathrm{C}$ NMR in a mixture of $\mathrm{CDCl}_{3}$ with minimum amount of HFIP (Figure S1). When compared to the OPA11 precursor (Figure 3A), the incorporation of the dithiobenzoate is first evidenced by the changing of color from beige to red, then proven by the appearance of typical peaks at $7.90 \mathrm{ppm}(2 \mathrm{H})$ on ${ }^{1} \mathrm{H}$ NMR spectrum corresponding to aromatic protons of the CPADB (Figure 3B) and by the presence of a characteristic $\mathrm{C}=\mathrm{S}$ peak at $224.02 \mathrm{ppm}$ on ${ }^{13} \mathrm{C}$ NMR spectrum (Figure S1). The yields of functionalization were further determined from relative integration of CPADB end group peaks at $7.90 \mathrm{ppm}$ for the dithiobenzoate and of the $\mathrm{Ph}-\mathrm{CH}_{2}-\mathrm{N}$ - protons at $4.90 \mathrm{ppm}$ for the OPA11 backbone (Figure 3B). 


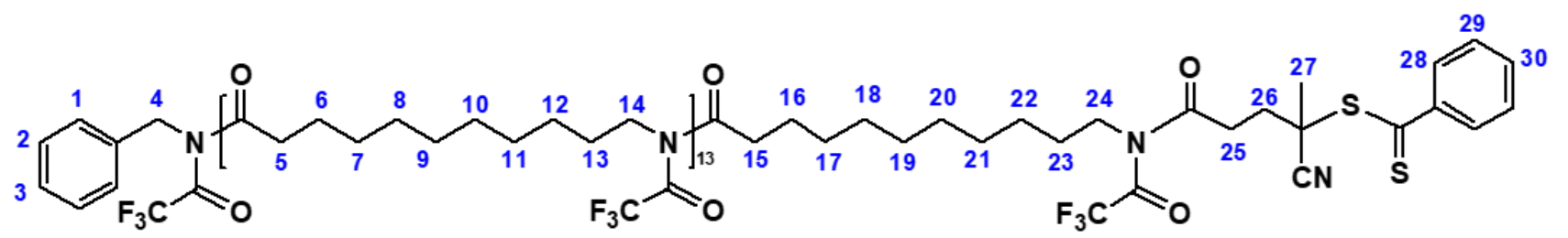

B)
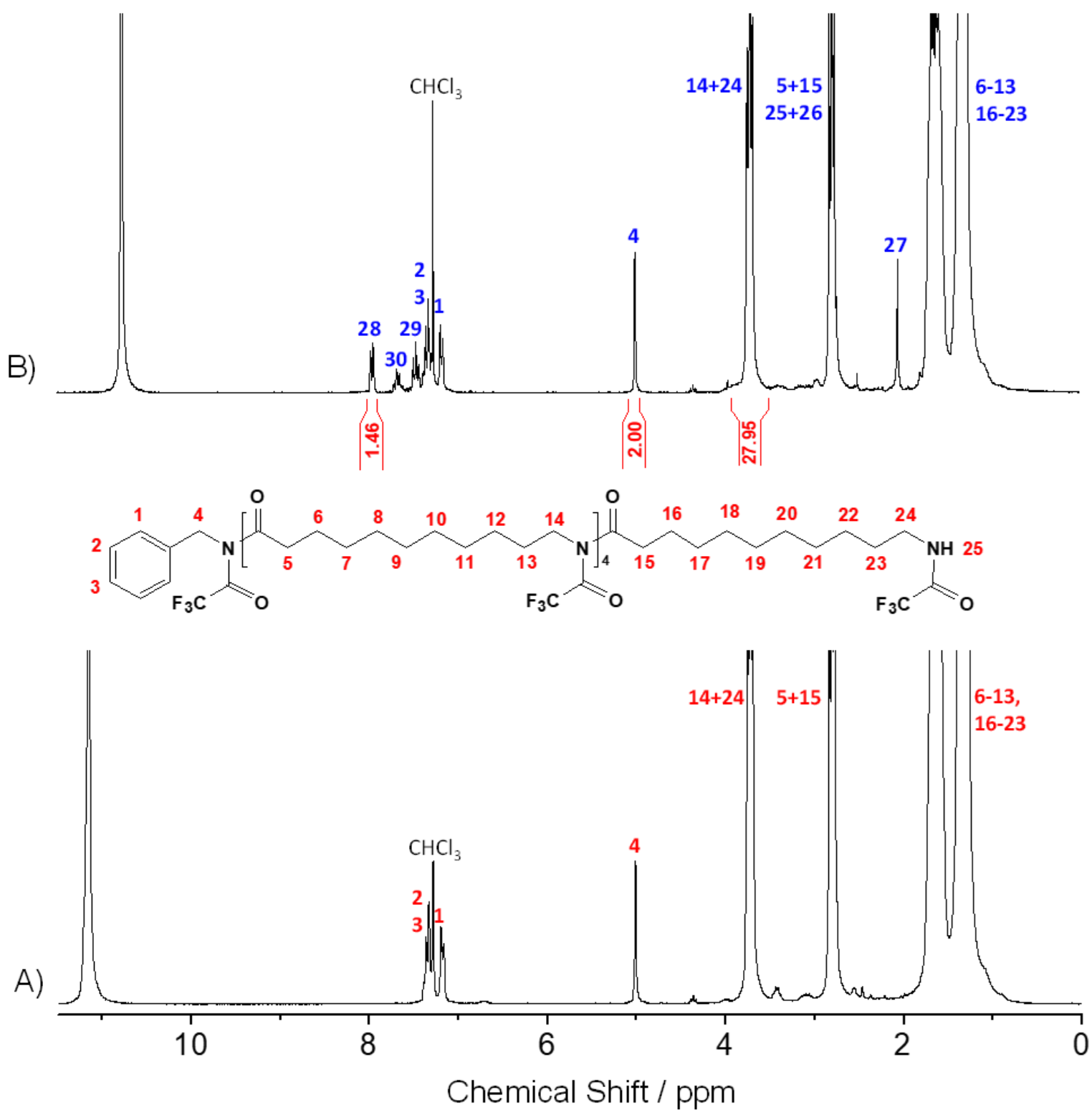

Figure 3: ${ }^{1} \mathrm{H}$ NMR spectra of (A) TFAA-modified OPA11 $\left(D P_{n}=6\right)$, and (B) TFAA-modified OPA11CPADB $\left(D P_{n}=15\right)$, recorded in $\mathrm{CDCl}_{3}$ at $25{ }^{\circ} \mathrm{C}$. Note: the signals due to $\mathrm{H}_{2} \mathrm{O}$ and trifluoroacetic acid (TFA) are in fast exchange, finally giving rise to the signals at $12.3 \mathrm{ppm}$ (A) and $11.7 \mathrm{ppm}$ (B), respectively, these peak positions are due to very high $\mathrm{TFA} / \mathrm{H}_{2} \mathrm{O}$ molar ratio. ${ }^{38}$ 
The optimized oligoamides functionalization yield with NHS-functionalized dithiobenzoate ranges from $72 \%$ for the longest OPA11 $\left(D P_{n}=15\right)$, to $77 \%$ for the shortest OPA11 $\left(D P_{n}=6\right)$ suggesting a slight negative influence of the OPA11 backbone length on the functionalization extent (Table 2). Although the quantitative functionalization of OPA11 via CPADB is not achieved, functionalization yields are comparable to values reported in the literature with other polymers. ${ }^{39,40}$

Characterization of the resulting oligoRAFT agents by DSC revealed similar thermal properties as their amine-functionalized OPA11 precursors, the shortest ones $\left(D P_{\mathrm{n}}=6\right.$ and 10) still display a complex thermal behavior with several different endothermic peaks (including the similar major peak at respectively 152 and $163{ }^{\circ} \mathrm{C}$ ). In all cases, crystallinity ratios around 30\% are measured (Table 2).

Table 2: Properties of OPA11-CPADB.

\begin{tabular}{cccc}
\hline $\begin{array}{c}\text { DP }{ }_{n} \text { of OPA11- } \\
C P A D B\end{array}$ & $\begin{array}{c}\text { Functionality }^{\mathrm{a}} \\
\%\end{array}$ & $\begin{array}{c}T_{m}{ }^{\mathrm{b}} \\
{ }^{\circ} C\end{array}$ & $\begin{array}{c}X_{\mathrm{c}}{ }^{\mathrm{b}} \\
\%\end{array}$ \\
\hline 6 & 77 & 153 & 32 \\
10 & 73 & 162 & 34 \\
15 & 72 & 172 & 31 \\
\hline
\end{tabular}

a: Determined by ${ }^{1} \mathrm{H}$ NMR in $\mathrm{CDCl}_{3}$ at $25^{\circ} \mathrm{C}$, (samples are trifluoroacetylated with TFAA prior to perform ${ }^{1} \mathrm{H} \mathrm{NMR}$ ), from relative integration of methylene protons of the benzyl end group and aromatic protons of the dithiobenzoate group. ${ }^{\mathrm{b}}$ : Obtained from DSC analysis ( $2^{\text {nd }}$ cycle), $\Delta \mathrm{H}_{\mathrm{c} \infty}=206 \mathrm{Jg}^{-1}$ for $100 \%$ crystalline PA11. ${ }^{36}$

Synthesis of OPA11-b-PLMA diblock copolymers. The capability of the oligomer-functionalized RAFT agents to grow macromolecular blocks in a controlled manner was subsequently investigated. OPA11-CPADB mediated polymerizations of lauryl methacrylate were carried out at $60{ }^{\circ} \mathrm{C}$ in HFIP/toluene $(1 / 1, \mathrm{v} / \mathrm{v})$ in the presence of AIBN $([\mathrm{CTA}] /[\mathrm{AIBN}]=20)$. As shown in Figure S2, whatever the degree of polymerization of the oligoamides, pseudo-first order kinetics are observed.

For each CPADB-functionalized oligoamide, molar masses grow with conversion and dispersity ranging from 1.24 to 1.37 are measured (Table 3 and Figure 4). We further investigated the conditions 
allowing for purifying the OPA11-b-PLMA diblock copolymers from traces of unfunctionalized OPA11, and unreacted OPA11-CPADB. In this view, HFIP was proven to selectively precipitate the BCP (which appears as a pink sticky gel) providing that the molar mass of the PLMA block is higher than $30000 \mathrm{~g} / \mathrm{mol}$.
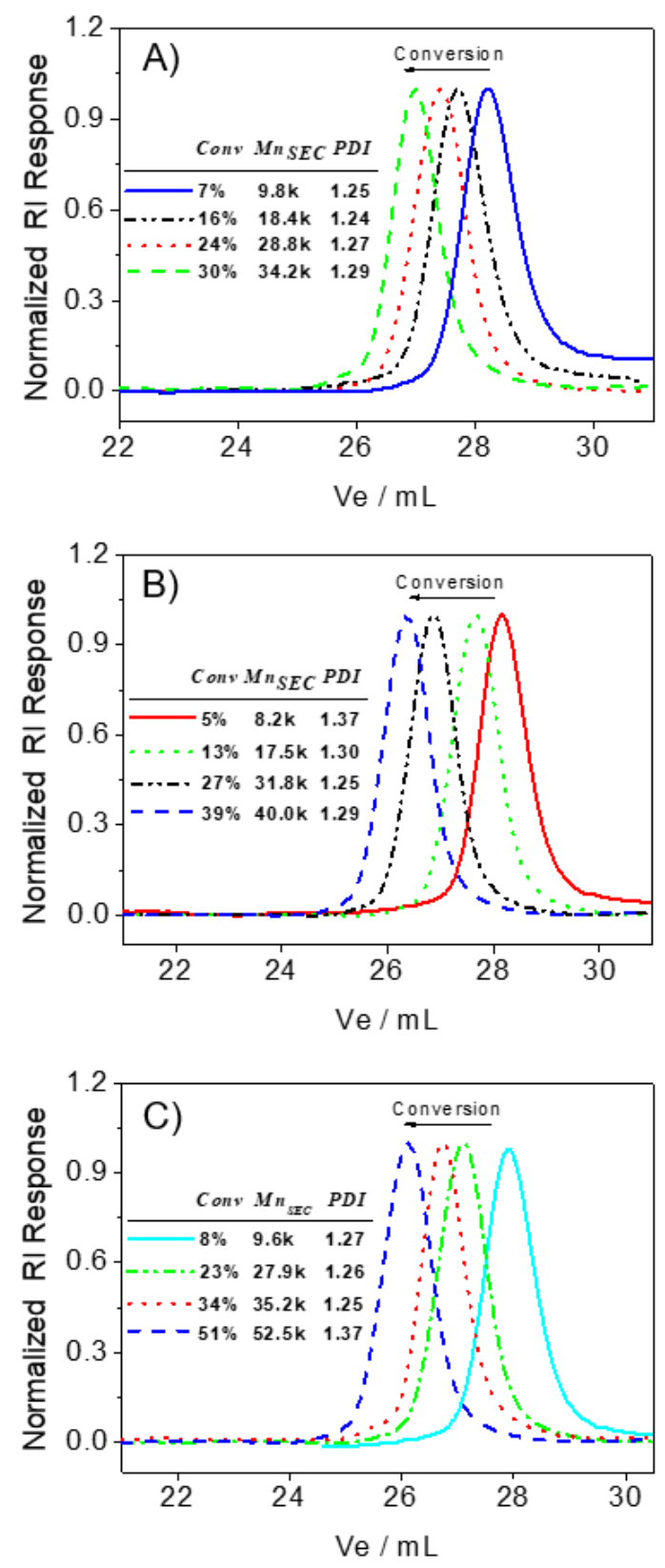
Figure 4: SEC traces for the solution polymerization of LMA in HFIP/toluene $(1 / 1, \mathrm{v} / \mathrm{v})$ at $60{ }^{\circ} \mathrm{C}$ mediated by OPA11-CPADB using AIBN as initiator: $[\mathrm{M}] /[\mathrm{CTA}]=400,[\mathrm{CTA}] /[$ Initiator $]=20$. $(\mathrm{A}$ : $\left.D P_{n}=6 ; \mathrm{B}: D P_{n}=10 ; \mathrm{C}: D P_{n}=15\right)$.

Table 3: Properties of the RAFT-made OPA11- $b$-PLMA diblock copolymers.

\begin{tabular}{|c|c|c|c|c|c|c|c|c|}
\hline & {$[\mathrm{M}] /$} & $\operatorname{Conv}^{a}$ & $M_{n t h}{ }^{b}$ & $M_{n N M R}{ }^{c}$ & $M_{n S E C}{ }^{d}$ & & $T_{m}^{e}$ & $\overline{X_{c}^{e}}$ \\
\hline Sample & [CTA] & $\%$ & $\mathrm{~kg} / \mathrm{mol}$ & $\mathrm{kg} / \mathrm{mol}$ & $\mathrm{kg} / \mathrm{mol}$ & $\bigoplus^{d}$ & ${ }^{o} \mathrm{C}$ & $\%$ \\
\hline$(\mathrm{OPA} 11)_{6}-b-\mathrm{P}(\mathrm{LMA})_{29}$ & 400 & 7 & 8.1 & 8.9 & 9.8 & 1.25 & -- & -- \\
\hline$(\mathrm{OPA} 11)_{6}-b-\mathrm{P}(\mathrm{LMA})_{57}$ & 400 & 16 & 17 & 15.9 & 18.4 & 1.24 & -- & -- \\
\hline$(\mathrm{OPA} 11)_{6}-b-\mathrm{P}(\mathrm{LMA})_{99}$ & 400 & 24 & 25.4 & 26.7 & 28.8 & 1.27 & -- & -- \\
\hline$(\mathrm{OPA} 11)_{6}-b-\mathrm{P}(\mathrm{LMA})_{115}$ & 400 & 30 & 31.5 & 30.7 & 34.2 & 1.29 & 152 & 35 \\
\hline$(\mathrm{OPA} 11)_{10}-b-\mathrm{P}(\mathrm{LMA})_{30}$ & 400 & 5 & 6.8 & 9.5 & 8.2 & 1.37 & -- & -- \\
\hline$(\mathrm{OPA} 11)_{10^{-}} b-\mathrm{P}(\mathrm{LMA})_{57}$ & 400 & 13 & 14.8 & 16.3 & 17.5 & 1.30 & -- & -- \\
\hline$(\mathrm{OPA} 11)_{10}-b-\mathrm{P}(\mathrm{LMA})_{101}$ & 400 & 27 & 28.9 & 27.5 & 31.8 & 1.25 & -- & -- \\
\hline$(\mathrm{OPA} 11)_{10^{-}} b-\mathrm{P}(\mathrm{LMA})_{162}$ & 400 & 39 & 41.4 & 42.9 & 40 & 1.29 & 163 & 30 \\
\hline$(\mathrm{OPA} 11)_{15}-b-\mathrm{P}(\mathrm{LMA})_{162}$ & 400 & 8 & 9.8 & 8.3 & 9.6 & 1.27 & -- & -- \\
\hline$(\mathrm{OPA} 11)_{15}-b-\mathrm{P}(\mathrm{LMA})_{103}$ & 400 & 23 & 26 & 29.3 & 27.9 & 1.26 & -- & -- \\
\hline$(\mathrm{OPA} 11)_{15}-b-\mathrm{P}(\mathrm{LMA})_{138}$ & 400 & 34 & 36.8 & 37.6 & 35.2 & 1.25 & 172 & 33 \\
\hline$(\mathrm{OPA} 11)_{15}-b-\mathrm{P}(\mathrm{LMA})_{204}$ & 400 & 51 & 54.4 & 56.7 & 52.5 & 1.37 & -- & -- \\
\hline
\end{tabular}

a: Conversion from ${ }^{\mathrm{I}} \mathrm{H}$ NMR. ${ }^{\mathrm{b}}$ : Number-average molecular weight evaluated from the following equation: $\mathrm{M}_{\mathrm{n}, \mathrm{th}}=\mathrm{Conv} \times([\mathrm{M}] /[\mathrm{CTA}]) \times \mathrm{m}_{\mathrm{M}}+\mathrm{m}_{\mathrm{CTA}} \cdot{ }^{\mathrm{c}}$ : Determined from relative integration of the methylene protons of the benzyl group and PLMA backbone protons. ${ }^{\mathrm{d}}$ : From SEC in THF (PMMA calibration, triple detection) after trifluoroacetylation of the OPA11 segment ${ }^{\mathrm{e}}$ : Obtained from DSC analysis $\left(2^{\text {nd }}\right.$ cycle) with $\Delta \mathrm{H}_{\mathrm{c} \infty}=206 \mathrm{~J}^{\circ} \mathrm{g}^{-1}$ for $100 \%$ crystalline PA11, ${ }^{36}$ taking into account the weight fraction of OPA11 in the obtained diblock copolymers. 
${ }^{1} \mathrm{H}$ NMR analysis gave clear evidence of the efficient purification approach. After precipitation, similar integrations are indeed observed for the characteristic peak of the two methylene protons of benzyl end group located in $\alpha$ position $(2 \mathrm{H}$ at $4.90 \mathrm{ppm}$ ) and for the two aromatic protons of the dithiobenzoate (at $7.78 \mathrm{ppm}$ ), suggesting that all the residual unfunctionalized OPA11 has been extracted (Figure 5). Furthermore, the presence of peaks at 2.69 and $3.60 \mathrm{ppm}$ corresponding to the methylene groups next to $-\mathrm{NH}$ - and $-\mathrm{C}(=\mathrm{O})$ - groups are consistent with the effective bonding of OPA11 to PLMA chain. The molar mass of the PLMA blocks was finally evaluated by ${ }^{1} \mathrm{H}$ NMR $\left(\mathrm{CDCl}_{3} / \mathrm{TFAA}\right)$ from the relative integration of protons in the PLMA backbone $\left(-\mathrm{O}-\mathrm{CH}_{2}-\mathrm{C}_{11} \mathrm{H}_{23}, 2 \mathrm{n} H, \delta=3.86 \mathrm{ppm}\right.$, with $\mathrm{n}$ being the degree of polymerization) and of protons of OPA11 backbone (-NH- $\mathrm{CH}_{2}-\mathrm{CH}_{2-}, 2 \times 15 \mathrm{H}$, $\delta=2.69 \mathrm{ppm}$, with 15 being the repeat units of OPA11).

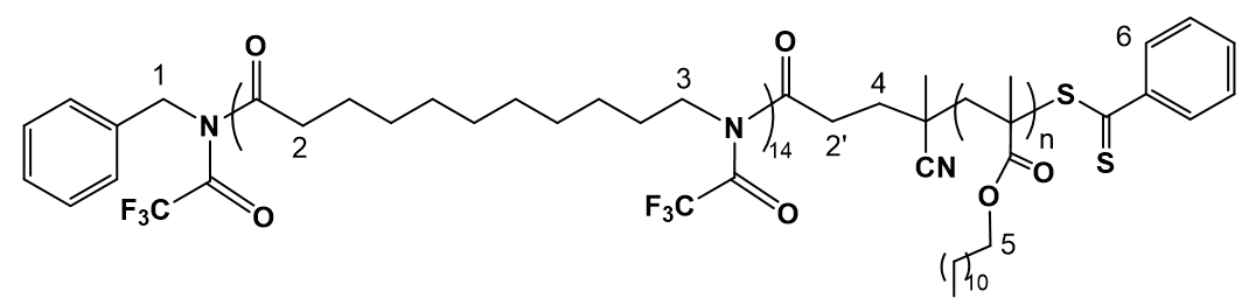

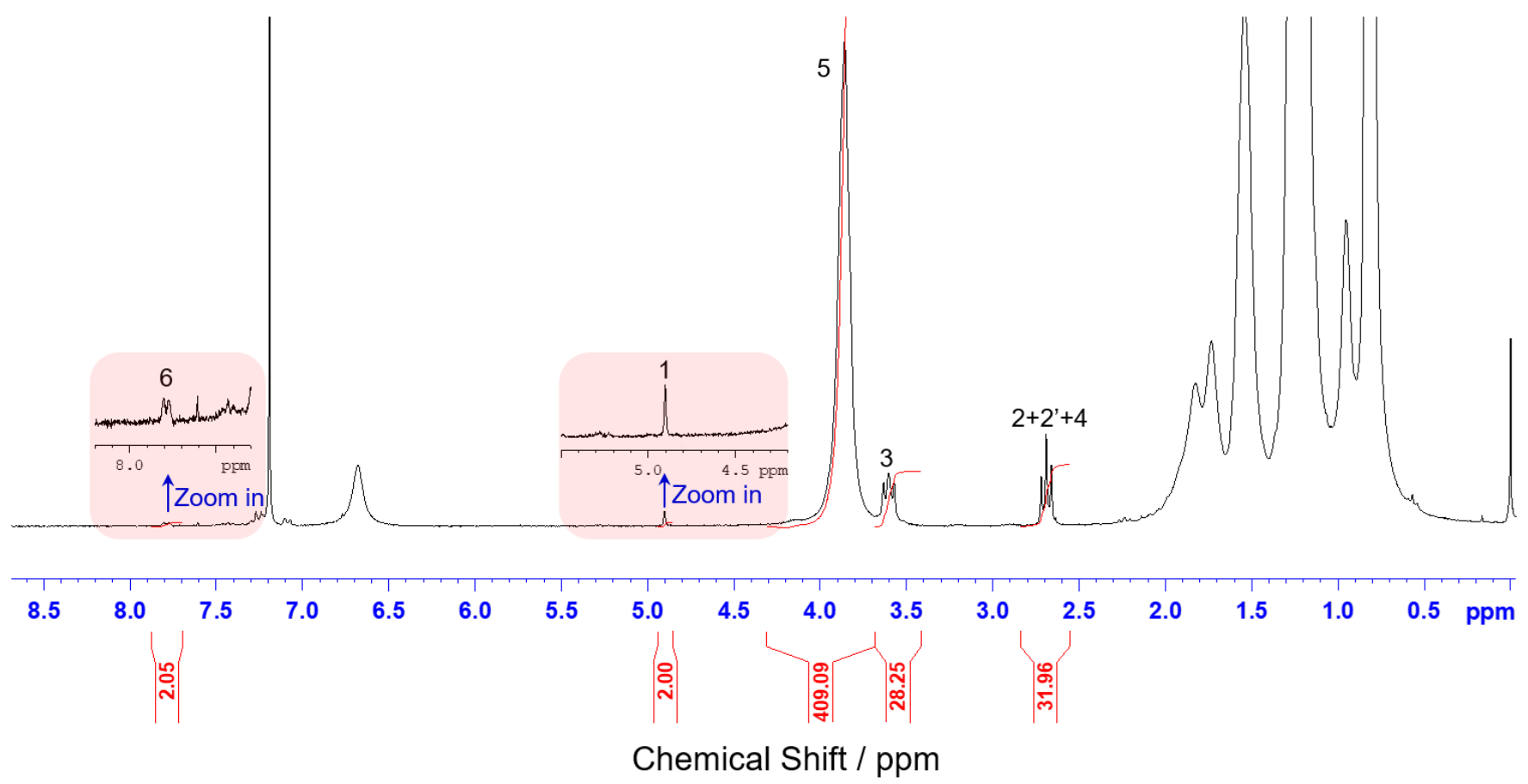


Figure 5: ${ }^{1} \mathrm{H}$ NMR spectra of TFAA-modified (OPA11) $)_{15}-b$-P(LMA) $)_{204}$ recorded in $\mathrm{CDCl}_{3}$ at $25{ }^{\circ} \mathrm{C}$. Note: the signals due to $\mathrm{H}_{2} \mathrm{O}$ and TFA are in fast exchange, finally giving rise to a signal at 6.8 ppm, the peak position is due to relative low $\mathrm{TFA} / \mathrm{H}_{2} \mathrm{O}$ molar ratio. ${ }^{38}$

The thermal properties of the resulting diblock copolymer were subsequently investigated by DSC. As shown in Figure 6 and Table 3, the formation of the diblock copolymer is assessed by the concomitant presence of a glass transition temperature at $-55{ }^{\circ} \mathrm{C}$ corresponding to the PLMA block and of melting temperatures $\left(152-172{ }^{\circ} \mathrm{C}\right)$ attributed to the OPA11 block. Interestingly, the presence of the PLMA block does not strongly affect the crystallinity of the OPA11 segments. Even though the weakest endothermic peaks (observed at $127{ }^{\circ} \mathrm{C}$ for OPA10 and 121 and $96{ }^{\circ} \mathrm{C}$ for OPA6, see Figure 2) are hardly visible after chain extension, very similar $T_{\mathrm{m}}$ (for the main endothermic peak) and crystallinity ratio are obtained for OPA11- $b$-PLMA and OPA11 precursors.

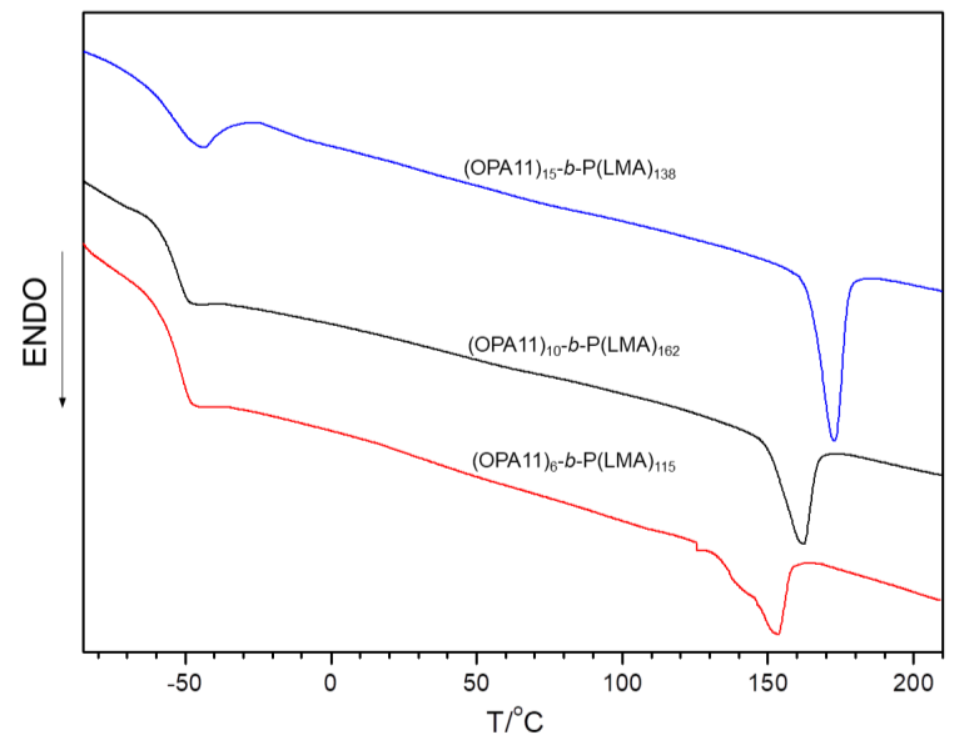

Figure 6: DSC traces of the obtained OPA11- $b$-PLMA diblock copolymers with different $D P_{n}$ of OPA11 ( $2^{\text {nd }}$ cycle $)$.

\section{Synthesis of OPA11- $b$-PLMA- $b$-PMMA triblock copolymers.}


Aiming at incorporating our BCPs as nanostructuring agents for epoxy thermosets, we subsequently investigated the chain extension of (OPA11) $\left.{ }_{15}-b-\mathrm{P}(\mathrm{LMA})_{138}, M_{\mathrm{n} \mathrm{NMR}}=37.6 \mathrm{~kg}^{\prime} \mathrm{mol}^{-1}, \nexists=1.25\right)$ with MMA whose resulting homopolymer has been previously proven to stay miscible with DGEBA/MCDEA epoxy system upon network polymerization. ${ }^{33-35}$ Thanks to the combined presence of miscible PMMA and immiscible PLMA and OPA blocks, we anticipated that the targeted BCP would self-organize at the nanometer scale in the final material. Therefore, a series of (OPA11) $5^{-} b$ P(LMA) ${ }_{138-b-(M M A)}$ y triblock copolymers have been prepared. As can be seen in Figure 7, Table 4 and Figure S3, the chain extension follows a typical controlled polymerization process. The molar mass increases linearly with conversion while the dispersity stays below 1.4.

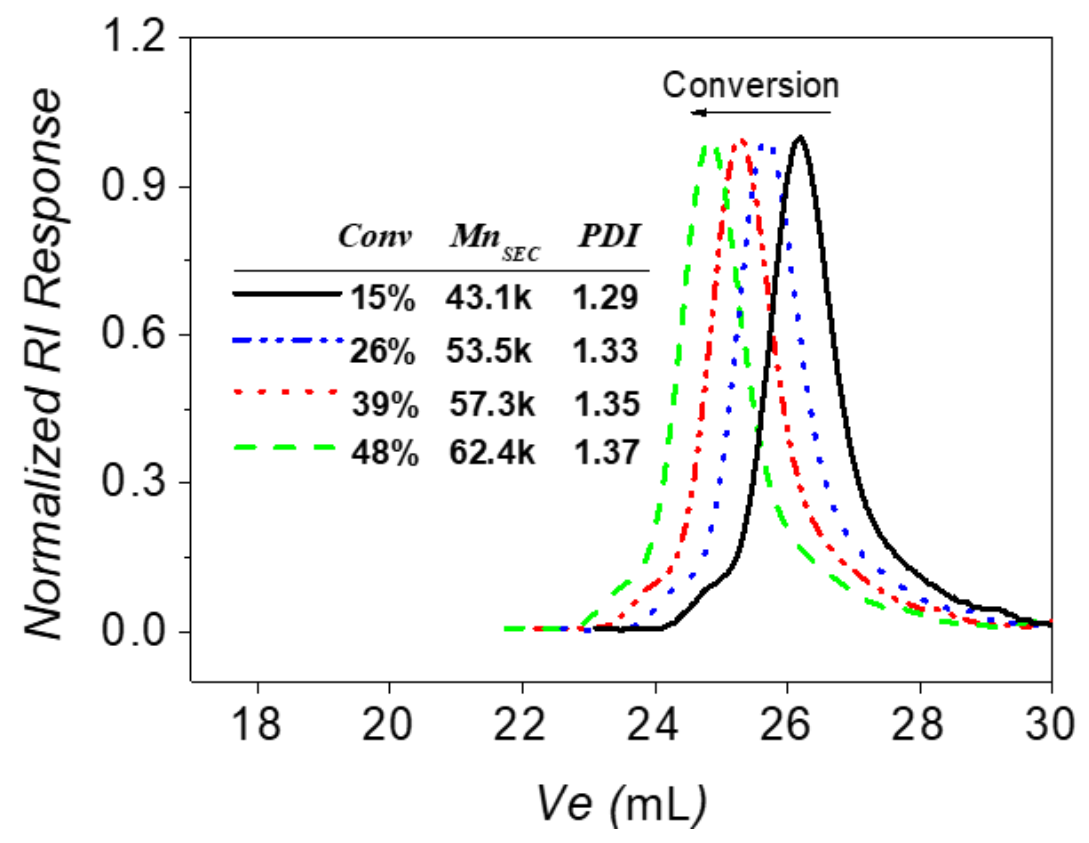

Figure 7: SEC traces for the solution polymerization of MMA in HFIP/toluene $(1 / 1, v / v)$ at $60{ }^{\circ} \mathrm{C}$ mediated by $(\mathrm{OPA} 11)_{15}-b-\mathrm{P}(\mathrm{LMA})_{138}$ using AIBN as initiator: $[\mathrm{M}] /[\mathrm{CTA}]=550,[\mathrm{CTA}] /[$ Initiator $]=20$, samples were modified with TFAA.

Table 4: Properties of the obtained OPA11-b-PLMA- $b$-PMMA triblock copolymers. 


\begin{tabular}{|c|c|c|c|c|c|c|c|c|}
\hline & {$[\mathrm{M}] /$} & $\operatorname{Conv}^{a}$ & $M_{n t h}{ }^{b}$ & $M_{n N M R}{ }^{c}$ & $M_{n S E C}{ }^{d}$ & & $T_{m}^{e}$ & $\overline{X_{c}^{e}}$ \\
\hline Sample & [CTA] & $\%$ & $\mathrm{~g} / \mathrm{mol}$ & $\mathrm{g} / \mathrm{mol}$ & $\mathrm{g} / \mathrm{mol}$ & $\bigoplus^{d}$ & ${ }^{\circ} \mathrm{C}$ & $\%$ \\
\hline$(\mathrm{OPA} 11)_{15}-b-\mathrm{P}(\mathrm{LMA})_{138^{-}-b-\mathrm{P}(\mathrm{MMA})_{26}}$ & 550 & 15 & 45.9 & 40.2 & 43.1 & 1.29 & -- & -- \\
\hline$(\mathrm{OPA} 11)_{15}-b-\mathrm{P}(\mathrm{LMA})_{138}-b-\mathrm{P}(\mathrm{MMA})_{121}$ & 550 & 26 & 52 & 49.7 & 53.5 & 1.33 & -- & -- \\
\hline$(\mathrm{OPA} 11)_{15}-b-\mathrm{P}(\mathrm{LMA})_{138}-b-\mathrm{P}(\mathrm{MMA})_{152}$ & 550 & 39 & 59.2 & 52.8 & 57.3 & 1.35 & -- & -- \\
\hline 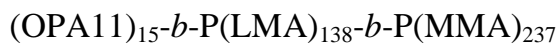 & 550 & 48 & 64 & 60.8 & 62.4 & 1.37 & 171 & 32 \\
\hline
\end{tabular}

\footnotetext{
${ }^{\mathrm{a}}$ : Conversion from ${ }^{1} \mathrm{H}$ NMR. ${ }^{\mathrm{b}}$ : Number-average molecular weight was evaluated from the following equation: $M_{\mathrm{n}, \text { th }}=\mathrm{Conv} \times([\mathrm{M}] /[\mathrm{CTA}]) \times \mathrm{m}_{\mathrm{M}}+\mathrm{m}_{\mathrm{CTA}}$. ${ }^{\mathrm{c}}$ : Determined from relative integration of the benzyl amine peaks and polymer backbone peaks. ${ }^{\mathrm{d}}$ : From SEC in THF (PMMA calibration, triple detection), after modification with TFAA ${ }^{\mathrm{e}}$ : Obtained from DSC analysis $\left(2^{\text {nd }}\right.$ cycle), $\Delta \mathrm{H}_{\mathrm{c} \infty}=206 \mathrm{~J}^{\prime} \mathrm{g}^{-1}$ for $100 \%$ crystalline PA $11,{ }^{36}$ taking into account the weight fraction of OPA11 in the obtained triblock copolymers.
}

Moreover, an excellent agreement is found between theoretical and experimental molar masses evaluated by SEC and ${ }^{1} \mathrm{H}$ NMR (from relative integration of protons in the PMMA backbone $-\mathrm{O}-\mathrm{CH}_{3}$, $3 \mathrm{mH}, \delta=3.54 \mathrm{ppm}$, with $\mathrm{m}$ being the degree of polymerization and of protons of OPA11 backbone $\mathrm{NH}-\mathrm{CH}_{2}-\mathrm{CH}_{2^{-}}, 2 \times 14 \mathrm{H}, \delta=2.69 \mathrm{ppm}$, with 14 being the repeat units of OPA11) indeed consistent with a controlled process (Figure 8). 


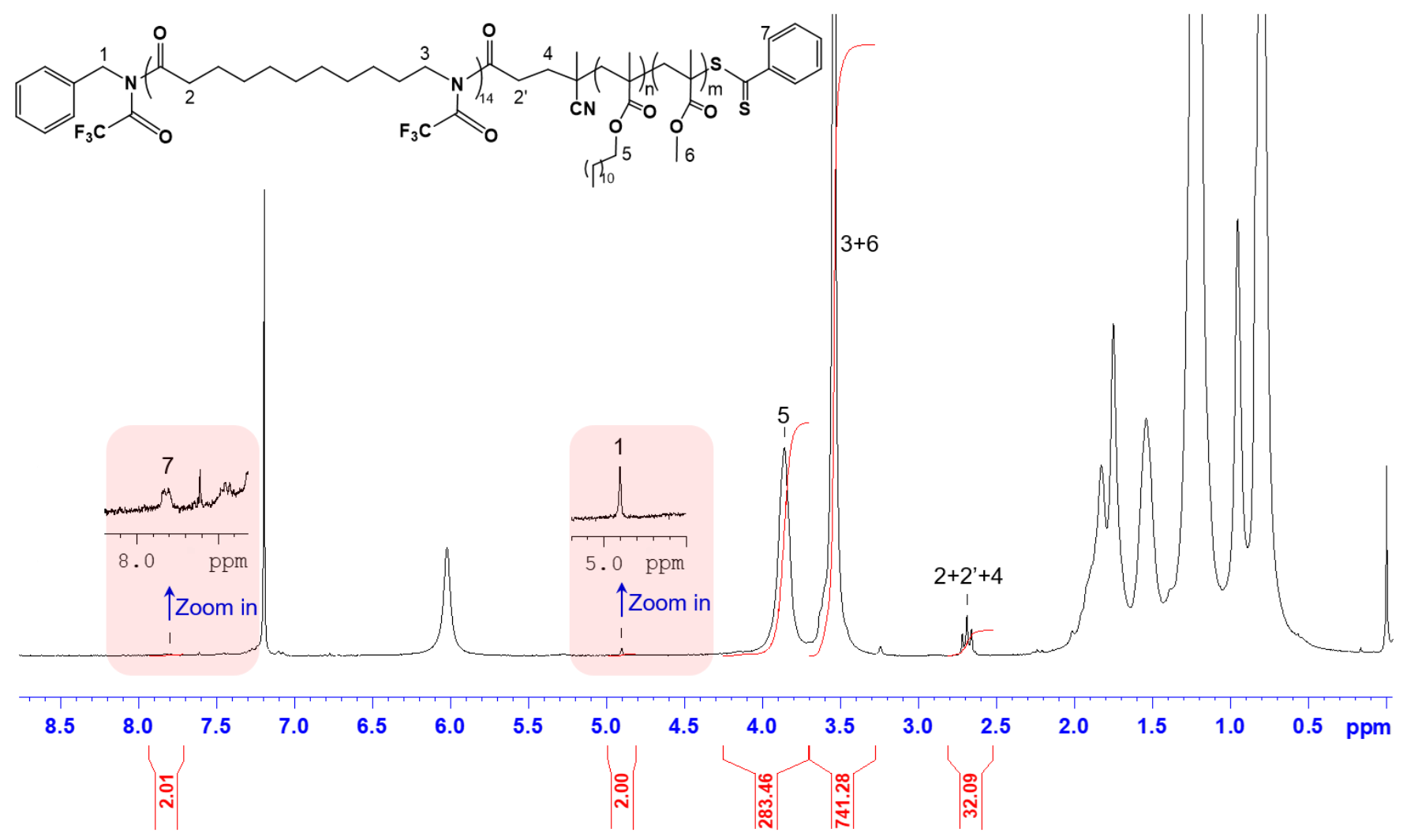

Chemical Shift / ppm

Figure 8: ${ }^{1} \mathrm{H}$ NMR spectrum of TFAA-modified $(\mathrm{OPA} 11)_{15}-b-\mathrm{P}(\mathrm{LMA})_{138}-b-\mathrm{P}(\mathrm{MMA})_{237}$ recorded in $\mathrm{CDCl}_{3}$ at $25{ }^{\circ} \mathrm{C}$. Note: the signals due to $\mathrm{H}_{2} \mathrm{O}$ and TFA are in fast exchange, finally giving rise to the signal at $6.0 \mathrm{ppm}$, the peak position is due to the relative low $\mathrm{TFA} / \mathrm{H}_{2} \mathrm{O}$ molar ratio. ${ }^{38}$

The formation of the semi-crystalline elastomeric glassy OPA11- $b$-PLMA- $b$-PMMA triblock was assessed by DSC analysis (Figure 9). The glass transition temperatures of the PLMA and PMMA blocks are clearly observed respectively at -55 and $115{ }^{\circ} \mathrm{C}$ respectively, as well as a melting temperature $\left(T_{\mathrm{m}}=\right.$ $171{ }^{\circ} \mathrm{C}$ ) confirming the ability of the OPA11 segment to crystallize. This phenomenon confirms the microphase separation occurring between OPA11 and the two other blocks. Again, the crystalline properties of OPA11 segment incorporated in the triblock $\left(T_{\mathrm{m}}, \mathrm{X}_{\mathrm{c}}\right)$ are very similar to those exhibited by neat OPA11 highlighting that the presence of the methacrylate backbone does not hinder the crystallization process. 


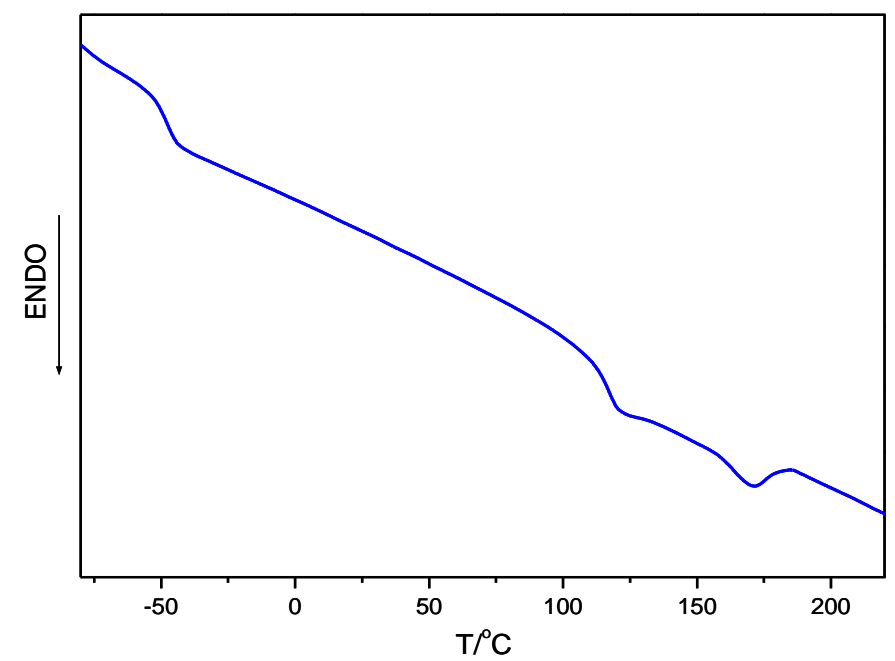

Figure 9: DSC curve of (OPA11) $)_{15}-b-\mathrm{P}(\mathrm{LMA})_{138}-b-\mathrm{P}(\mathrm{MMA})_{237}, 2^{\text {nd }} c y c l e$.

Morphology of crystalline-rubbery-glassy ABC triblock copolymers as films. The morphology of $(\mathrm{OPA} 11)_{15}-b-\mathrm{P}(\mathrm{LMA})_{138}-b-\mathrm{P}(\mathrm{MMA})_{237}$ was subsequently investigated by AFM (tapping mode). For this purpose, a copolymer/dichloromethane (DCM) solution (2 g/L) was deposited by spin-coating onto ozone-treated silicon wafers. The resulting film was further cured for 3 days at $180{ }^{\circ} \mathrm{C}$ under vacuum to promote mobility and organization of the BCP chains. AFM characterization gave clear evidence that $(\mathrm{OPA} 11)_{15}-b-\mathrm{P}(\mathrm{LMA})_{138}-b-\mathrm{P}(\mathrm{MMA})_{237}$ phase-separates into nanostructured bulk material (Figure 10A). The collected pictures indicate that the triblock adopts a morphology where the glassy PMMA domains (Figure 10B, red arrows pointed) are surrounded by the soft PLMA matrix which also contains additional nanodomains that may be the signature of crystalline OPA11 domains (Figure 10B, blue arrows pointed). 


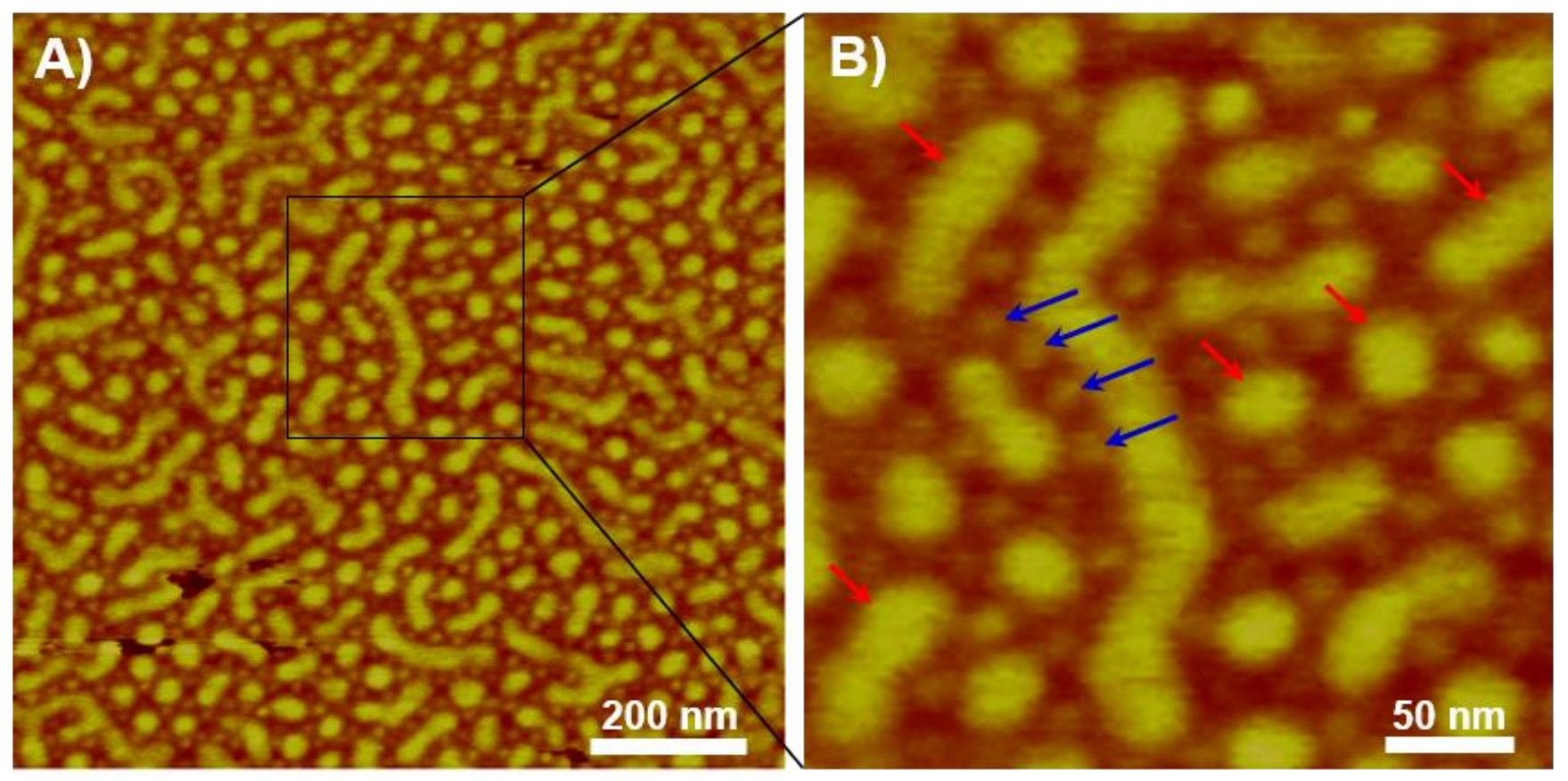

Figure 10: AFM Phase images of $(\mathrm{OPA} 11)_{15}-b-\mathrm{P}(\mathrm{LMA})_{138}-b-\mathrm{P}(\mathrm{MMA})_{237}$. Sample was prepared via spin coating, 2g/L in DCM.

\section{Morphology of crystalline-rubbery-glassy ABC triblock copolymers in epoxy matrix.}

We subsequently investigated the generation of (OPA11) ${ }_{15}-b-\mathrm{P}(\mathrm{LMA})_{138}-b-\mathrm{P}(\mathrm{MMA})_{237}$ nanostructures into a thermoset material obtained from a reactive mixture of DGEBA epoxy and MCDEA as comonomer. In the present case, the PMMA block is known to stay miscible in DGEBA-MCDEA mixture up to the end of the network polymerization, ${ }^{33-35}$ while OPA11 and PLMA blocks are expected to phaseseparate upon curing. First, the solubility of (OPA11) ${ }_{15}-b-\mathrm{P}(\mathrm{LMA})_{138}-b-\mathrm{P}(\mathrm{MMA})_{237}$ into DGEBA epoxy was checked, i.e., the BCP was fully dissolved after $30 \mathrm{~min}$ of mechanical stirring at $180{ }^{\circ} \mathrm{C}$ and for concentrations as high as $20 \mathrm{phr}$ (per hundred epoxy resin, corresponding to $11 \mathrm{wt} \%$ ). The obtained solutions were then mixed with MCDEA over 5 min and casted on PTFE moulds, subsequently placed into an oven and polymerized for $24 \mathrm{~h}$ at $80{ }^{\circ} \mathrm{C}$, then $24 \mathrm{~h}$ at $135{ }^{\circ} \mathrm{C}$ and post-reacted for $24 \mathrm{~h}$ at $180{ }^{\circ} \mathrm{C}$ to ensure full curing of the samples. 
All the cured samples are transparent assessing that no macrophase separation occurs during the reactive mixture polymerization. TEM images show the formation of nanostructured epoxy networks. As illustrated by Figure 11 and Figure S4, (OPA11) $15-b-\mathrm{P}(\mathrm{LMA})_{138}-b-\mathrm{P}(\mathrm{MMA})_{237}$ triblock copolymers self-assemble into spherical micelles with diameters on the order of $20 \mathrm{~nm}$ that are homogeneously dispersed in the epoxy matrix. These micelles are formed before the gel point of the growing network is reached (either upon dissolution in the reactive system or in the course of the polymerization) and persist upon full curing. ${ }^{33,34}$ We believe that the bright core of the micelles is mainly composed of PLMA while PMMA blocks form a swollen corona and remain embedded in the epoxy network. ${ }^{35}$ The presence of a dark corona in between is due to the OPA11 blocks which are selectively stained by ruthenium tetraoxide. ${ }^{41}$ As anticipated, higher triblock copolymer contents (varying from 5 to 20 phr, i.e. 3 to 11 wt\%) result in larger amount of micelles but do not influence neither micelles size nor nanodomains organization.
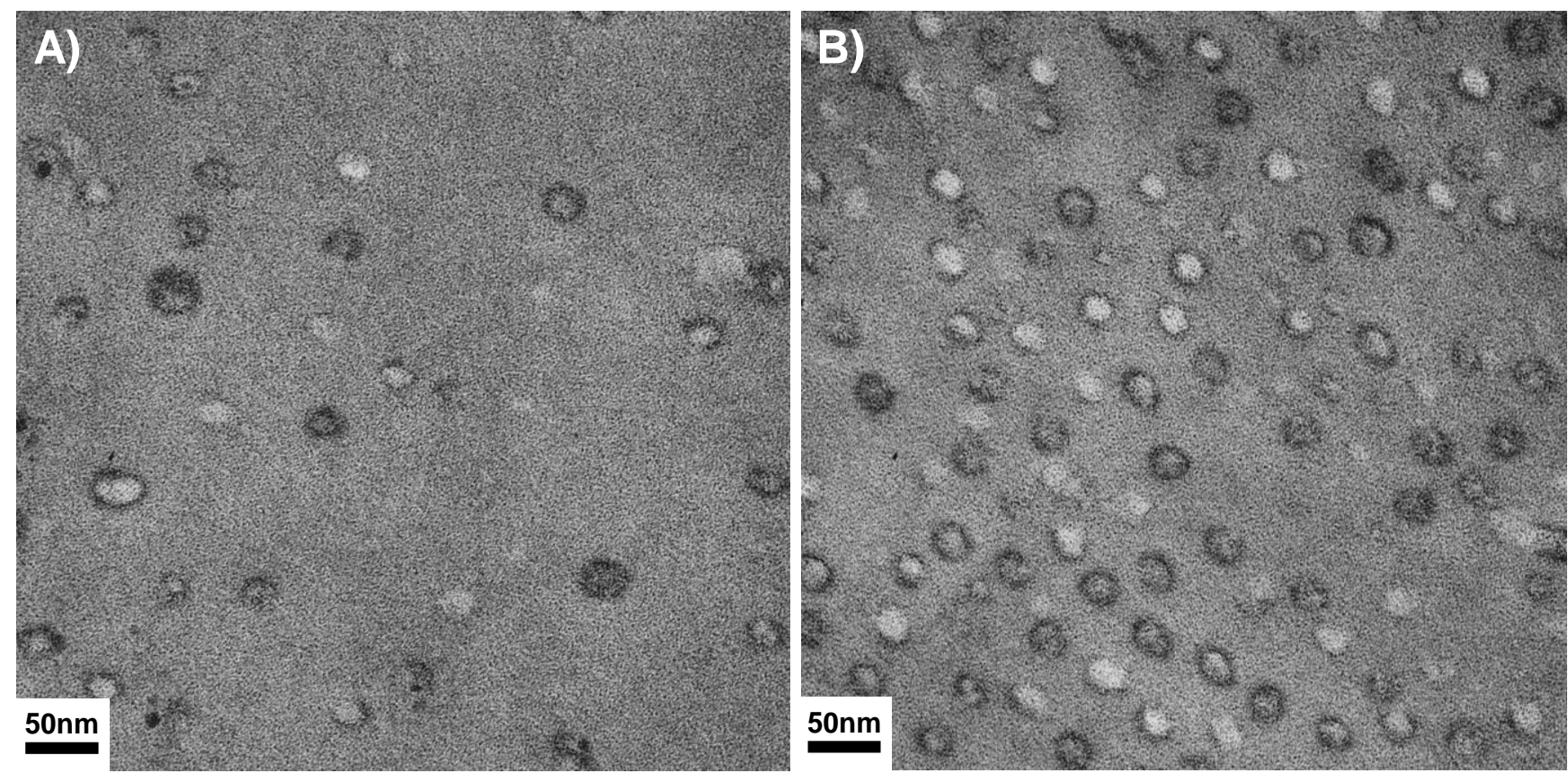

Figure 11: TEM images of nanostructured epoxy networks generated from $5 \mathrm{phr}(3 \mathrm{wt} \%, \mathrm{~A})$ and $20 \mathrm{phr}$ $(11 \mathrm{wt} \%, \mathrm{~B})$ of (OPA11) $)_{15}-b-\mathrm{P}(\mathrm{LMA})_{138}-b-\mathrm{P}(\mathrm{MMA})_{237}$ triblock copolymers. 


\section{CONCLUSIONS}

Relying on a straightforward synthetic path and benefiting from the crystallization ability of oligoamides, this paper reports on the successful synthesis of diverse semi-crystalline-rubbery-glassy $\mathrm{ABC}$ triblock copolymers. First, three OPA11s of different molar masses were successfully synthesized by melt polycondensation using a chain stopper to afford a good control over the chain length. Then CPADB-based oligoRAFT agents were generated with functionalization yields higher than $70 \%$. All OPA11-functionalized oligoRAFT agents were proven to efficiently mediate the polymerization of laurylmethacrylate affording OPA11- $b$-PLMA diblock copolymers. Targeting the design of nanostructured epoxy-amine networks, well-defined OPA11- $b$-PLMA- $b$-PMMA semi-crystallinerubbery-glassy triblock copolymers were ultimately prepared. After confirmation of their ability to selforganize as conventional $\mathrm{BCPs}$ by $\mathrm{AFM}$, incorporation of $(\mathrm{OPA} 11)_{15}-b-\mathrm{P}(\mathrm{LMA})_{138}-b-\mathrm{P}(\mathrm{MMA})_{237}$ triblock copolymer in DGEBA/MCDEA formulations was proven to promote the formation of nanostructured epoxy-based thermosets. As shown by TEM images, the triblock copolymer forms welldispersed spherical micelles with diameters of $\sim 20 \mathrm{~nm}$ within the network. The core of the micelles is constituted of PLMA whereas PMMA forms the outer shell of the nanostructures and OPA11 is located in between. The described synthetic strategy and the proposed BCP structures may contribute to future efforts aiming at developing new nanostructured networks.

\section{AUTHOR INFORMATION}

\section{Corresponding Authors}

*E-mail: julien.bernard@insa-lyon.fr (J. Bernard)

*E-mail: jtzhu@ @ust.edu.cn (J. Zhu)

*E-mail: senbin@ hust.edu.cn (S. Chen) 


\section{Author Contributions}

The manuscript was written through contributions of all authors. All authors have given approval to the final version of the manuscript.

\section{Funding Sources}

The authors gratefully acknowledge the National Natural Science Foundation of China (21801085), Program for HUST Academic Frontier Youth Team (2015-01), the Chinese Scholarship Council for SC grant and the French Ministry of Research - ANR (SUPRABLOCK 08-JCJC-0083). The authors thank the "Centre des Microtechnologies de l'Université Lyon 1" (CT $\mu$ ) for providing access to TEM facilities.

\section{Supporting Information}

${ }^{13} \mathrm{C}$ NMR of OPA11-CPAD, and first-order kinetic plots for all the solution polymerizations, supplementary TEM images of nanostructured epoxy networks (Figure S1-S4).

\section{REFERENCES:}

(1) Spontak, R. J.; Patel, N. P.: Thermoplastic Elastomers: Fundamentals and Applications. Curr. Opin. Colloid In. 2000, 5, 333-340.

(2) Handbook of Thermoplastic Elastomers (2nd Edition); Publisher: Elsevier Inc.: Place Published: United States, 2014.

(3) Hillmyer, M. A.; Lipic, P. M.; Hajduk, D. A.; Almdal, K.; Bates, F. S.: Self-Assembly and Polymerization of Epoxy Resin-Amphiphilic Block Copolymer Nanocomposites. Journal of the American Chemical Society 1997, 119, 2749-2750.

(4) Dean, J. M.; Verghese, N. E.; Pham, H. Q.; Bates, F. S.: Nanostructure Toughened Epoxy Resins. Macromolecules 2003, 36, 9267-9270.

(5) Hermel, T. J.; Hahn, S. F.; Chaffin, K. A.; Gerberich, W. W.; Bates, F. S.: Role of Molecular Architecture in Mechanical Failure of Glassy/Semicrystalline Block Copolymers: CEC vs CECEC Lamellae. Macromolecules 2003, 36, 2190-2193.

(6) Spencer, R. K. W.; Matsen, M. W.: Domain Bridging in Thermoplastic Elastomers of Star Block Copolymer. Macromolecules 2017, 50, 1681-1687.

(7) Zhang, J.; Li, T.; Mannion, A. M.; Schneiderman, D. K.; Hillmyer, M. A.; Bates, F. S.: Tough and Sustainable Graft Block Copolymer Thermoplastics. ACS Macro Lett. 2016, 5, 407-412.

(8) Chang, A. B.; Bates, F. S.: The ABCs of Block Polymers. Macromolecules 2020, 53, 2765-2768. 
(9) Wang, W.; Lu, W.; Goodwin, A.; Wang, H.; Yin, P.; Kang, N.-G.; Hong, K.; Mays, J. W.: Recent Advances in Thermoplastic Elastomers from Living Polymerizations: Macromolecular Architectures and Supramolecular Chemistry. Prog. Polym. Sci. 2019, 95, 1-31.

(10) Bates, F. S.; Hillmyer, M. A.; Lodge, T. P.; Bates, C. M.; Delaney, K. T.; Fredrickson, G. H.: Multiblock Polymers: Panacea or Pandora's Box? Science 2012, 336, 434-440.

(11) Park, C.; De Rosa, C.; Fetters, L. J.; Thomas, E. L.: Influence of an Oriented Glassy Cylindrical Microdomain Structure on the Morphology of Crystallizing Lamellae in a Semicrystalline Block Terpolymer. Macromolecules 2000, 33, 7931-7938.

(12) Beckingham, B. S.; Register, R. A.: Architecture-Induced Microphase Separation in Nonfrustrated A-B-C Triblock Copolymers. Macromolecules 2013, 46, 3486-3496.

(13) Burns, A. B.; Register, R. A.: Thermoplastic Elastomers via Combined Crystallization and Vitrification from Homogeneous Melts. Macromolecules 2016, 49, 269-279.

(14) Yang, J.-X.; Pan, L.; Ma, Z.; Wang, B.; Li, Y.-S.: Syntheses and Properties of ABA, CBA, and CBC Triblock Copolymers Based Thermoplastic Elastomers with Glassy (A), Elastomeric (B), and Crystalline (C) Blocks. J. Macromol. Sci. A 2019, 56, 225-233.

(15) Wang, R.-Y.; Wang, X.-Y.; Fan, B.; Xu, J.-T.; Fan, Z.-Q.: Microphase Separation and Crystallization Behaviors of Bi-Phased Triblock Terpolymers with a Competitively Dissolved Middle Block. Polymer 2017, 117, 140-149.

(16) Schmalz, H.; Böker, A.; Lange, R.; Krausch, G.; Abetz, V.: Synthesis and Properties of ABA and ABC Triblock Copolymers with Glassy (A), Elastomeric (B), and Crystalline (C) Blocks. Macromolecules 2001, 34, 8720-8729.

(17) Mahanthappa, M. K.; Lim, L. S.; Hillmyer, M. A.; Bates, F. S.: Control of Mechanical Behavior in Polyolefin Composites: Integration of Glassy, Rubbery, and Semicrystalline Components. Macromolecules 2007, 40, 1585-1593.

(18) Zhang, J.; Schneiderman, D. K.; Li, T.; Hillmyer, M. A.; Bates, F. S.: Design of Graft Block Polymer Thermoplastics. Macromolecules 2016, 49, 9108-9118.

(19) Bezuidenhout, D.; Williams, D. F.; Zilla, P.: Polymeric Heart Valves for Surgical Implantation, Catheter-Based Technologies and Heart Assist Devices. Biomaterials 2015, 36, 6-25.

(20) Wieduwild, R.; Tsurkan, M.; Chwalek, K.; Murawala, P.; Nowak, M.; Freudenberg, U.; Neinhuis, C.; Werner, C.; Zhang, Y.: Minimal Peptide Motif for Non-covalent Peptide-Heparin Hydrogels. J. Am. Chem. Soc. 2013, 135, 2919-2922.

(21) Sandeau, A.; Mazières, S.; Vergelati, C.; Corriol, C.; Destarac, M.: Dixanthate-terminated poly(butylene terephthalate). A novel RAFT/MADIX agent for the synthesis of well-defined triblock copolymers resulting from consecutive step- and chain-growth polymerization processes. Polym. Chem. 2011, 2, 2490-2499.

(22) Sandeau, A.; Mazières, S.; Destarac, M.: Well-defined macromolecular architectures through consecutive condensation and reversible-deactivation radical polymerizations. Polymer 2012, 53, 56015618 .

(23) Gegenhuber, T.; De Keer, L.; Goldmann, A. S.; Van Steenberge, P. H. M.; Mueller, J. O.; Reyniers, M.-F.; Menzel, J. P.; D’hooge, D. R.; Barner-Kowollik, C.: Fusing Light-Induced StepGrowth Processes with RAFT Chemistry for Segmented Copolymer Synthesis: A Synergetic Experimental and Kinetic Modeling Study. Macromolecules 2017, 50, 6451-6467.

(24) Mahanthappa, M. K.; Hillmyer, M. A.; Bates, F. S.: Mechanical Consequences of Molecular Composition on Failure in Polyolefin Composites Containing Glassy, Elastomeric, and Semicrystalline Components. Macromolecules 2008, 41, 1341-1351. 
(25) Fleury, G.; Bates, F. S.: Structure and Properties of Hexa- and Undecablock Terpolymers with Hierarchical Molecular Architectures. Macromolecules 2009, 42, 3598-3610.

(26) Ruiz-Pérez, L.; Royston, G. J.; Fairclough, J. P. A.; Ryan, A. J.: Toughening by Nanostructure. Polymer 2008, 49, 4475-4488.

(27) Pang, V.; Thompson, Z. J.; Joly, G. D.; Bates, F. S.; Francis, L. F.: Adhesion Strength of Block Copolymer Toughened Epoxy on Aluminum. ACS Appl. Polym. Mater. 2020, 2, 464-474.

(28) Zhou, Q.; Liu, Q.; Yu, Y.; Zhuang, Y.; Lv, Y.; Xiao, H.; Song, N.; Ni, L.: Morphological Evolution and Mechanical Properties of an "Anchor Chain" Nanodomain Structure of a Reactive Amphiphilic Triblock Copolymer in Epoxy Resin. Polym. Chem. 2020, 11, 3615-3626.

(29) Kishi, H.; Kunimitsu, Y.; Imade, J.; Oshita, S.; Morishita, Y.; Asada, M.: Nano-Phase Structures and Mechanical Properties of Epoxy/Acryl Triblock Copolymer Alloys. Polymer 2011, 52, 760-768.

(30) Heng, Z.; Zhang, X.; Chen, Y.; Zou, H.; Liang, M.: In-Situ Construction of "Octopus"-Like Nanostructure to Achieve High Performance Epoxy Thermosets. Chem. Eng. J. 2019, 360, 542-552.

(31) Micro- and Nanostructured Epoxy/Rubber Blends; Wiley-VCH Verlag GmbH \& Co. KGaA, 2014; Vol. Editors: Sabu Thomas, Christophe Sinturel, Raju Thomas.

(32) Bathfield, M.; D'Agosto, F.; Spitz, R.; Charreyre, M.-T.; Delair, T.: Versatile Precursors of Functional RAFT Agents. Application to the Synthesis of Bio-Related End-Functionalized Polymers. $J$. Am. Chem. Soc. 2006, 128, 2546-2547.

(33) Ritzenthaler, S.; Court, F.; David, L.; Girard-Reydet, E.; Leibler, L.; Pascault, J. P.: ABC Triblock Copolymers/Epoxy-Diamine Blends. 1. Keys To Achieve Nanostructured Thermosets. Macromolecules 2002, 35, 6245-6254.

(34) Ritzenthaler, S.; Court, F.; Girard-Reydet, E.; Leibler, L.; Pascault, J. P.: ABC Triblock Copolymers/Epoxy-Diamine Blends. 2. Parameters Controlling the Morphologies and Properties. Macromolecules 2003, 36, 118-126.

(35) Deng, Y.; Bernard, J.; Alcouffe, P.; Galy, J.; Dai, L.; Gérard, J.-F.: Nanostructured Hybrid Polymer Networks from In Situ Self-Assembly of RAFT-Synthesized POSS-Based Block Copolymers. J. Polym. Sci. A 2011, 49, 4343-4352.

(36) CRC Handbook of Chemistry and Physics. 88ed 2007, Editor: Lide D. R., Publiser: Taylor \& Francis LLC, Place Published: London, ISBN: 0-8493-0488-1.

(37) Dencheva, N.; Nunes, T. G.; Oliveira, M. J.; Denchev, Z.: Crystalline Structure of Polyamide 12 as Revealed by Solid-State 13C NMR and Synchrotron WAXS and SAXS. Journal of Polymer Science Part B: Polymer Physics 2005, 43, 3720-3733.

(38) Ross, S. A.; Lowe, G.: Downfield Displacement of the NMR Signal of Water in Deuterated Dimethylsulfoxide by the Addition of Deuterated Trifluoroacetic Acid. Tetrahedron Lett. 2000, 41, 3225-3227.

(39) Theato, P.: Synthesis of well-defined polymeric activated esters. Journal of Polymer Science Part A: Polymer Chemistry 2008, 46, 6677-6687.

(40) Vinas, J.; Chagneux, N.; Gigmes, D.; Trimaille, T.; Favier, A.; Bertin, D.: SG1-based alkoxyamine bearing a N-succinimidyl ester: A versatile tool for advanced polymer synthesis. Polymer 2008, 49, 3639-3647.

(41) Trent, J. S.; Scheinbeim, J. I.; Couchman, P. R.: Ruthenium tetraoxide staining of polymers for electron microscopy. Macromolecules 1983, 16, 589-598. 
For the Table of Contents use only:

Title: Design of Semi-Crystalline Elastomeric Glassy Triblock Copolymers from Oligoamide-based RAFT Agents

Authors: Senbin Chen, Pierre Alcouffe, Alain Rousseau, Jean-François Gérard, Frédéric Lortie, Jintao

Zhu, and Julien Bernard

TOC Graph:

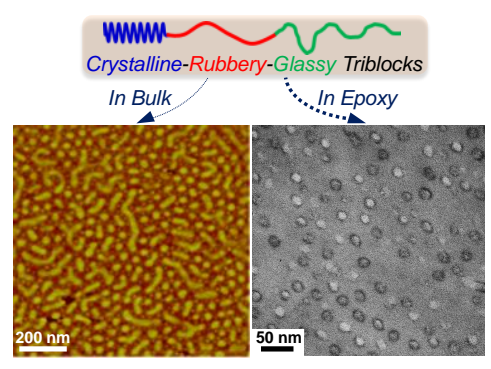

